Research Article

\title{
Dynamic Analysis of Multi-Stepped Functionally Graded Carbon Nanotube Reinforced Composite Plate with General Boundary Condition
}

\author{
Kwanghun Kim ${ }^{1},{ }^{1}$ Songhun Kwak, ${ }^{2}$ Yonguk Ri, ${ }^{1}$ Yongsong Paek, ${ }^{1}$ Wonjin Han, ${ }^{3}$ \\ and Kumchol Ri $\mathbf{i}^{3}$ \\ ${ }^{1}$ Department of Engineering Machine, Pyongyang University of Mechanical Engineering, Pyongyang 999093, \\ Democratic People's Republic of Korea \\ ${ }^{2}$ College of Mechanical Science and Technology, Kim Chaek University of Technology, Pyongyang 950003, \\ Democratic People's Republic of Korea \\ ${ }^{3}$ Department of Life Science, University of Science, Pyongyang 999093, Democratic People's Republic of Korea \\ Correspondence should be addressed to Kwanghun Kim; kimkwanghun@163.com
}

Received 14 February 2021; Accepted 30 June 2021; Published 14 July 2021

Academic Editor: Salvatore Caddemi

Copyright $\odot 2021$ Kwanghun Kim et al. This is an open access article distributed under the Creative Commons Attribution License, which permits unrestricted use, distribution, and reproduction in any medium, provided the original work is properly cited.

\begin{abstract}
This study presents the multi-stepped functionally graded carbon nanotube reinforced composite (FG-CNTRC) plate model for the first time, and its free and forced vibration is analyzed by employing the domain decomposition method. The segmentation technique is employed to discretize the structure along the length direction. The artificial spring technique is applied to the structural boundary and piecewise interface for satisfying the boundary conditions and the combined conditions between subplates. Based on this, the boundary conditions of subdomains could be considered as a free boundary constraint, reducing the difficulty in constructing the allowable displacement function. Since all the structures of subdomains are identical, the allowable displacement functions of them can be uniformly constructed using the two-dimensional ultraspherical polynomial expansion. The potential energy function of the plate is derived from the first-order shear deformation theory (FSDT). The allowable displacement function is substituted into the potential energy function, and then the natural frequencies and mode shapes of the multi-stepped FG-CNTRC plate are decided by using the Rayleigh-Ritz method. The accuracy and reliability of the proposed method are confirmed by the results of the previous literature and finite element method (FEM). On this basis, the influences of the geometric and material parameters on free and forced vibration of the multi-stepped FG-CNTRC plate are also studied.
\end{abstract}

\section{Introduction}

As the advanced manufacturing technology is rapidly developed, the FG-CNTRC has appeared as a prospective kind of composites in the past few years. The FG-CNTRC is composed of carbon nanotubes (CNTs) and functionally graded materials (FGMs) and considered as the advanced material with extraordinary mechanical, optical, thermal, and electrical features. Because of its excellent features, a lot of experimental and theoretical research studies have been conducted to study its mechanical and thermomechanical characteristics [1-5]. The basic research of Shen [6] on the bending behavior of CNT reinforced composite plates indicated that the bending moments of the plates can be significantly enhanced by introducing the functionally graded distribution of CNTs in a polymeric matrix. In addition, lots of efforts were made to study the FG-CNTRC beams, plates, and shells of various forms. Liew et al. [7] brilliantly summarized these investigations, in which the mechanical behavior of FG-CNTRC structures was described in detail including static vibration, dynamic vibration, free vibration, buckling and post-buckling, and linear 
and non-linear analysis. The wide range of investigations on the free vibration analysis has firstly paid attention to the analysis of the vibrational behavior of functionally graded materials [8-15]. Then, the research was enlarged to the analysis of the FG-CNTRC. The following paragraphs illustrate several research studies related to the analysis of the free vibration of FG-CNTRC shell structures. Applying the FSDT, Zhu et al. [16] studied the bending and free vibration behavior of thin-to-moderately thick FG-CNTRC plates by employing the finite element method. Zhang and his coauthors introduced several results on the vibrational behavior of FG-CNTRC rectangular [17], triangular [18], and skew [19] plates. In addition, Zhang et al. analyzed the free vibration characteristics of FG-CNTRC cylindrical panels [20]. In these articles, the FSDT theory and the kp-Ritz method were employed to obtain the governing equations of the cylindrical panels, and the influence of the distribution and volume fraction of CNTs was also studied.

Recently, an interesting study concerning the free vibration analysis of arbitrarily shaped FG-CNTRC plates was introduced by Fantuzzi et al. [21]. In this study, the FSDT theory was applied for the approximation of the displacement field of nanoplates, and the mapping of arbitrary shapes with holes and discontinuities of nanoplates reinforced by CNTs was conducted using the Non-Uniform Rational B-Spline (NURBS) curves. Based on the FSDT theory, Malekzadeh et al. [22, 23] analyzed the free vibration characteristics of laminated plates with FG-CNTRC layers using the differential quadrature method (DQM) for the numerical solutions. The comparative results of the natural frequencies, which were obtained by applying the extended rule of mixture, Eshelby-Mori-Tanaka method, and FSDT theory, respectively, were presented by Mehrabadi et al. [24]. The parametric studies were also provided, in this research, to analyze the effects of different kinds of CNTs and geometrical parameters on the free vibration characteristics of FG-CNTRC plates. In addition, Kiani studied the free vibration behavior of different types of FG-CNTRC plates [25] and skew plates [26]. Using the FSDT theory to describe the kinematics of the considered structure, Mirzaei and Kiani [27] employed the Ritz method to obtain the vibrational solutions, and they summarized the research studies mentioned above which were studying the influence of carbon nanotube reinforcements on the improvement of the vibrational behavior of FG-CNTRC structures. Mirzaei and Kiani applied the framework of the FSDT theory to investigate the natural frequencies of FG-CNTRC plates with cutout. In this research, the Ritz method with Chebyshev basis polynomials was used to find the numerical solutions, and it was shown that this solution method was effective for the arbitrary in-plane and out-of-plane boundary conditions of the FG-CNTRC plate. In other studies, Kiani applied the piezoelectric effect to the CNTRC plates [28], and the effect of electrical parameters on the fundamental frequency of FG-CNTRC piezoelectric plates was considered under the two kinds of electrical boundary conditions such as closed circuit and open circuit. Wang et al. [29] proposed a stepped functionally graded piezoelectric material (FGPM) plate model for the first time and studied its free and forced vibration by using the domain energy decomposition method. Based on the widely used FSDT, lots of other research studies on the free and forced vibrations analysis of FG-CNTRC plate structures have also been conducted [30-33]. Selim et al. [34] analyzed the free vibration behavior of FG-CNTRC plates based on Reddy's higher-order shear deformation theory (HSDT) and element-free kp-Ritz method in the thermal environment. Parametric effects such as CNT distribution, boundary conditions, plate aspect ratio, plate thickness-to-width ratio, and CNT volume fraction on the dimensionless frequencies were also examined. In the same way, Mehar et al. [35] conducted the vibration analysis of carbon nanotube reinforced composite plates. In addition, Wattanasakulpong and Chaikittiratana [36] studied the static and dynamic analysis of FG-CNTRC plates resting on the Pasternak elastic foundations. The governing equations were derived from the HSDT theory, and the accurate solutions were obtained to study the static as well as the vibrational behavior of such behavior. In addition, the vibration analysis of FG-CNTRC structures such as beam [37-41], panel [42-50], and shells [34, 51-58] has been also widely conducted.

As can be seen from the previous works, until now, the research on the FG-CNTRC plate has been mainly focused on the non-stepped plates with uniform thickness, and the multi-stepped FG-CNTRC plate has not been studied yet. Moreover, from the consideration of previous research studies, it can be known that it is still important to develop the simple and efficient integrated solution method for the free and forced vibration analysis of the multi-stepped plates. Therefore, the purpose of this study is to provide the integrated solution method for the free and forced vibration analysis of the multi-stepped FG-CNTRC plates. In this research, a unified modeling method is employed to construct the dynamic characteristic analysis model of multistepped FG-CNTRC plate. Within the framework of the domain decomposition method, the rectangular plates are segmented along the length direction using the segmenting technology, and then, the thickness of each subplate is taken differently, so that the stepped rectangular plates are constructed successfully. The potential boundary and combined conditions of segmented interfaces are obtained through the application of artificial spring technique. The allowable displacement functions in subdomains are established using the two-dimensional ultraspherical polynomials. In addition, the global potential energy functional of the multistepped FG-CNTRC plate is constructed by employing the FSDT. The polynomials' unknown coefficient is treated using the standard variational operation to study the dynamic characteristics of the FG-CNTRC plate. The convergence and accuracy of the proposed model are validated using numerical examples.

\section{Formulation}

2.1. Model of the Multi-Stepped FG-CNTRC Plate. Figure 1 shows the calculation model of the multi-stepped FG-CNTRC plate. As can be seen in Figure 1(a), the multistepped plate consists of several subplates with different 


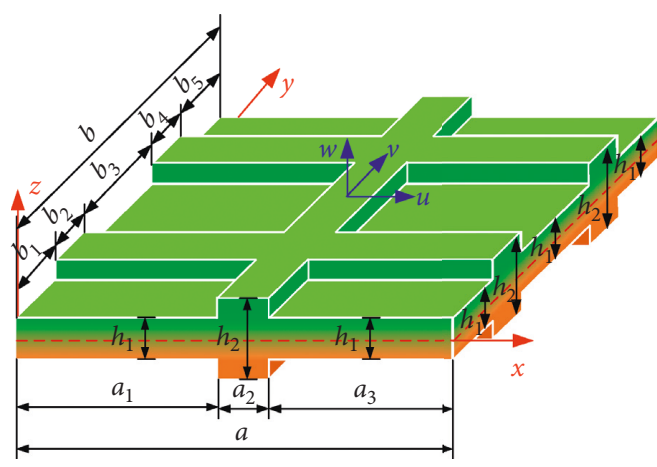

(a)

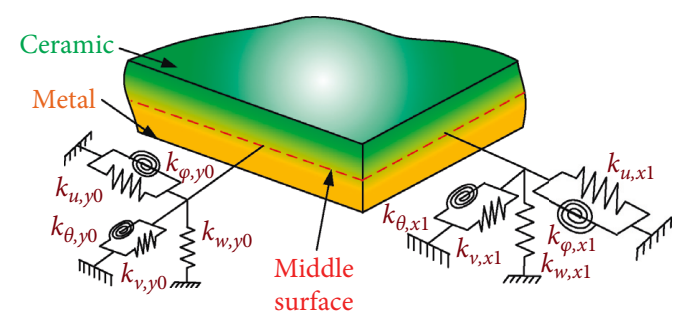

(b)

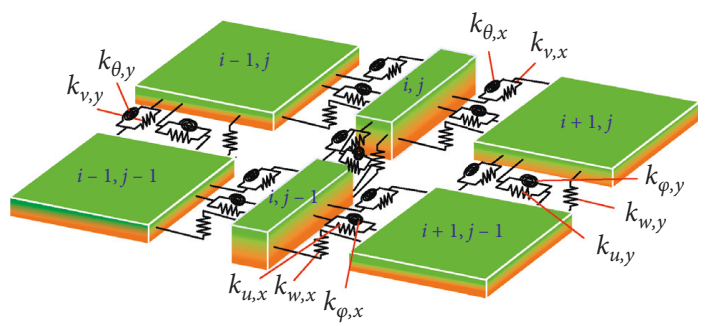

(c)

FIGURE 1: Multi-stepped FG-CNTRC plate model. (a) Geometric relationship. (b) Boundary condition. (c) Combined condition.

thicknesses in $x$ and $y$ directions, and the lengths of individual subplates are expressed as $a_{i}(i=1,2, \ldots)$ and $b_{j}(j=1$, $2, \ldots)$ in $x$ and $y$ directions, respectively.

Also, the heights of individual subplates are indicated as $h i$. In this research, the heights of individual subplates are expressed as $h_{1}$ and $h_{2}$ for the convenient calculation, and $u, v$, and $w$ are the displacements in $x, y, z$ directions, respectively. The artificial spring technique is introduced for the generalization of boundary conditions, and the four sides of the plate are modeled to be supported by the artificial springs (Figure $1(\mathrm{~b})$ ).

Each side has a boundary spring group consisting of three artificial springs $\left(k_{u}, k_{v}, k_{w}\right)$ and two rotating artificial elastic springs $\left(k_{\varphi}, k_{\theta}\right)$, and the boundary condition can be generalized by adjusting the stiffness of individual springs. The boundary conditions at four sides are expressed by adding subscript 0 at $x=0$ and $y=0$ boundary and subscript 1 at $x=a$ and $y=b$ boundary. The stepped plates can be seen to be made up of the strong combinations of the individual subplates, and the connective condition can be modeled in a similar way with the boundary condition. That is, by setting the stiffness of connective springs as infinity, the strong connective condition of individual plates can be accomplished. Figure 1(c) shows the connective conditions of individual plates.

2.2. Material Properties. The stepped plate considered here is composed of the isotropic matrix reinforced with CNTs. The distribution of CNTs in the matrix can be either uniform or functionally graded according to the thickness of plates. Figure 2 shows five types of CNT distributions such as UDCNTRC, FG- $\Lambda$ CNTRC, FG-V CNTRC, FG-X CNTRC, and FG-O CNTRC.
The CNT volume fractions $V_{\mathrm{CNT}}$ in the various kinds of FG-CNTRC plates are indicated as follows $[57,58]$ :

$$
V_{\mathrm{CNT}}(z)= \begin{cases}V_{\mathrm{CNT}}^{*}, & (\mathrm{UD}-\mathrm{CNT}), \\ \left(1+\frac{2 z}{h}\right) V_{\mathrm{CNT}}^{*}, & (\mathrm{FGV}-\mathrm{CNT}), \\ \left(1-\frac{2 z}{h}\right) V_{\mathrm{CNT}}^{*}, & (\mathrm{FG} \Lambda-\mathrm{CNT}), \\ 4 \frac{|z|}{h} V_{\mathrm{CNT}}^{*}, & (\mathrm{FGX}-\mathrm{CNT}), \\ 2\left(1-2 \frac{|z|}{h}\right) V_{\mathrm{CNT}}^{*}, & (\mathrm{FGO}-\mathrm{CNT}),\end{cases}
$$

in which

$$
V_{\mathrm{CNT}}^{*}=\frac{w_{\mathrm{CNT}}}{w_{\mathrm{CNT}}+\left(\rho_{\mathrm{CNT}} / \rho_{m}\right)-\left(\rho_{\mathrm{CNT}} / \rho_{m}\right) w_{\mathrm{CNT}}},
$$

where $w_{\mathrm{CNT}}$ is the mass fraction of nanotube and $\rho_{\mathrm{CNT}}$ and $\rho_{m}$ are the mass densities of CNT and matrix constituents, respectively.

Figure 3 shows the variation characteristics of CNT volume fractions $V_{\mathrm{CNT}}$ according to $z / h$ in five patterns. It shows that the value of $V_{\mathrm{CNT}}$ is constant regardless of thickness of plates in UD-CNTRC, while it increases or decreases in FG- $\Lambda$ CNTRC and FG-V CNTRC, respectively. In cases of FG-X CNTRC and FG-O CNTRC, the value of $V_{\text {CNT }}$ changes symmetrically about the middle surface. 


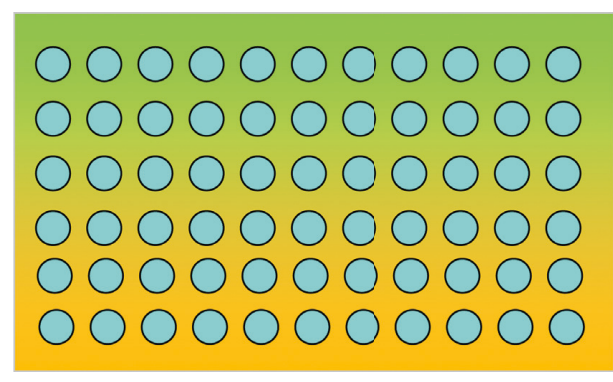

(a)

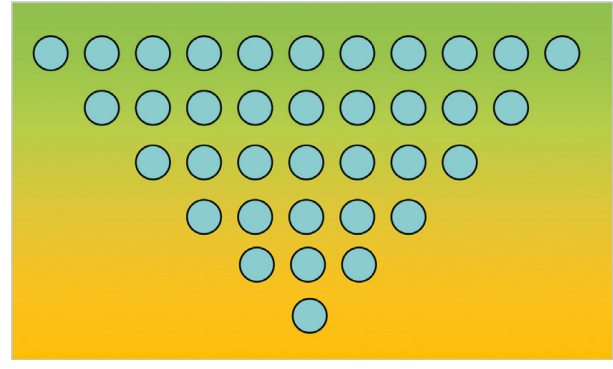

(c)

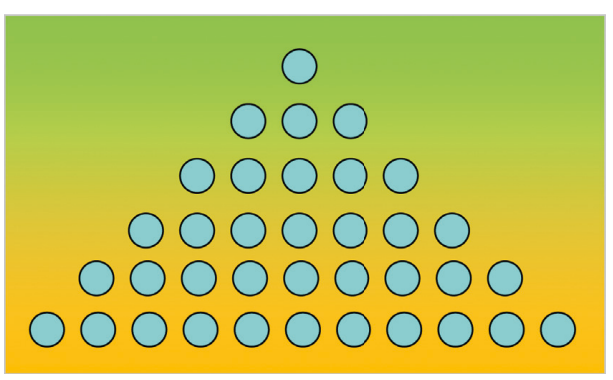

(b)

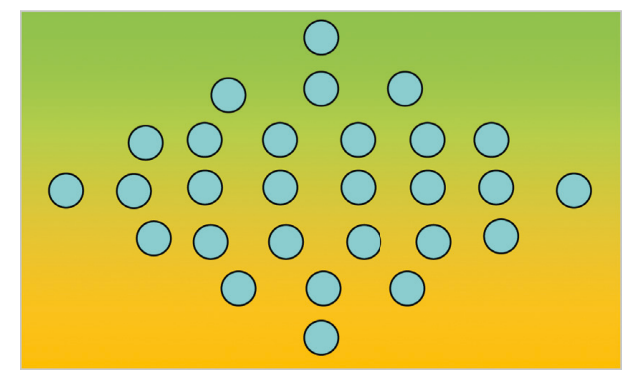

(d)

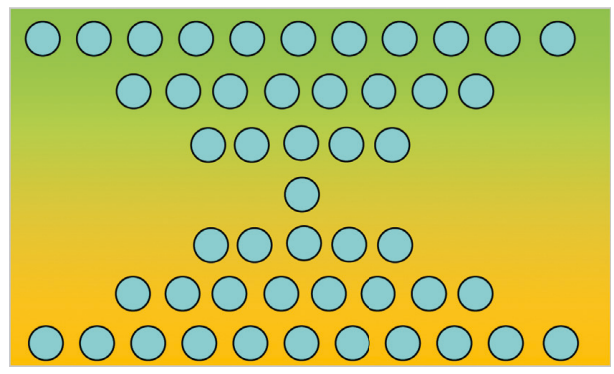

(e)

Figure 2: Distribution patterns of CNTs in FG-CNTRC plates. (a) UD-CNTRC. (b) FG- $\Lambda$ CNTRC. (c) FG-V CNTRC. (d) FG-O CNTRC. (e) FG-X CNTRC.

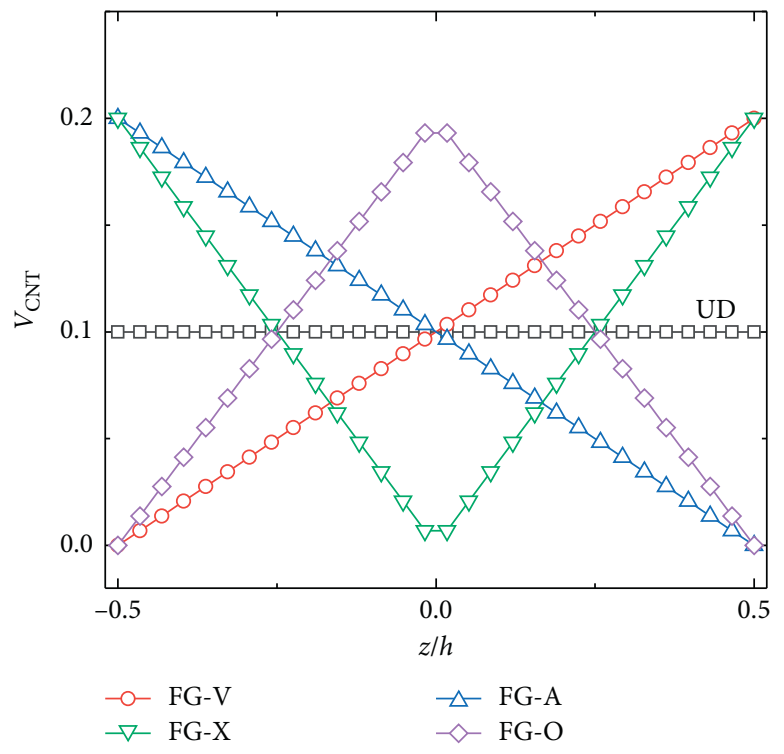

(a)

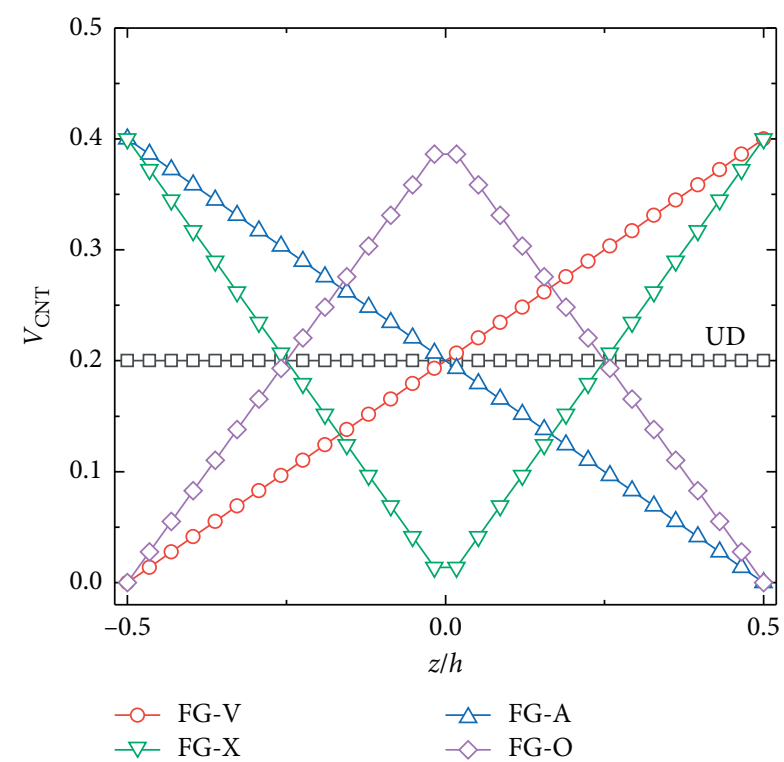

(b)

Figure 3: Change of the CNT volume fractions $V_{\mathrm{CNT}}$ on the thickness of plate. (a) $V_{\mathrm{CNT}}^{*}=0.1$. (b) $V_{\mathrm{CNT}}^{*}=0.2$. 
Based on the improved rule of mixtures, effective Young's modulus, shear modulus, Poisson's ratio, and mass density for CNTRC materials can be written as follows $[56,58]$ :

$$
\begin{aligned}
E_{11}(z) & =\eta_{1} V_{\mathrm{CNT}}(z) E_{11}^{\mathrm{CNT}}+V_{m}(z) E^{m}, \\
\frac{\eta_{2}}{E_{22}(z)} & =\frac{V_{\mathrm{CNT}}(z)}{E_{22}^{\mathrm{CNT}}}+\frac{V_{m}(z)}{E^{m}}, \\
\frac{\eta_{3}}{G_{12}(z)} & =\frac{V_{\mathrm{CNT}}(z)}{G_{12}^{\mathrm{CNT}}}+\frac{V_{m}(z)}{G^{m}}, \\
G^{m} & =\frac{E^{m}}{2\left(1-\mu^{m}\right)}, \\
\mu_{12}(z) & =V_{\mathrm{CNT}}(z) \mu_{12}^{\mathrm{CNT}}+V_{m}(z) \mu^{m}, \\
\mu_{21}(z) & =\frac{\mu_{12}(z)}{E_{11}(z)} E_{22}(z), \\
\rho(z) & =V_{\mathrm{CNT}}(z) \rho^{\mathrm{CNT}}+V_{m}(z) \rho^{m}, \\
V_{m}(z) & =1-V_{\mathrm{CNT}},
\end{aligned}
$$

where $E_{11}^{\mathrm{CNT}}, E_{22}^{\mathrm{CNT}}, G_{12}^{\mathrm{CNT}}, E^{m}, G^{m}$ represent Young's modulus and shear modulus of CNT and matrix, $\eta_{1}, \eta_{2}$, and $\eta_{3}$ are $\mathrm{CNT} /$ matrix efficiency parameters, and $\mu_{12}^{\mathrm{CNT}}, \mu^{m}$ denote Poisson's ratios of CNT and matrix.

2.3. Energy Function. The displacement components of the individual subplate can be expressed with the displacements of the midsurface and the rotations of the cross section using the FSDT as follows:

$$
\begin{aligned}
U^{i, j}(x, y, z, t) & =u_{0}^{i, j}(x, y, t)+z \varphi^{i, j}(x, y, t), \\
V^{i, j}(x, y, z, t) & =v_{0}^{i, j}(x, y, t)+z \theta^{i, j}(x, y, t), \\
W^{i, j}(x, y, z, t) & =w_{0}^{i, j}(x, y, t),
\end{aligned}
$$

where $u_{0}, v_{0}$, and $w_{0}$ represent the middle surface displacements of the $i$, jth subplate in the $x, y$, and $z$ directions, $\varphi$ and $\theta$ indicate the transverse normal rotations in regard to $x$ and $y$ axes, and $t$ denotes the time variable. The strain elements at a random point of the ith FG-CNTR subplate can be written as follows:

$$
\begin{aligned}
\varepsilon_{x x}^{i, j} & =\varepsilon_{x x, 0}^{i, j}+z \chi_{x x}^{i, j}, \\
\varepsilon_{y y}^{i, j} & =\varepsilon_{y y, 0}^{i, j}+z \chi_{y y}^{i, j}, \\
\gamma_{x y}^{i, j} & =\gamma_{x y, 0}^{i, j}+z \chi_{x y}^{i, j}, \\
\gamma_{x z}^{i, j} & =\gamma_{x z, 0}^{i, j}, \\
\gamma_{y z}^{i, j} & =\gamma_{y z, 0}^{i, j},
\end{aligned}
$$

where $\varepsilon_{x x, 0}^{i, j}, \varepsilon_{y y, 0}^{i, j}, \gamma_{x y, 0, j}^{i, j}, \gamma_{x z, 0}^{i, j}$, and $\gamma_{y z, 0}^{i, j}$ indicate the middle surface strains and $\chi_{x x}, \chi_{y y}^{i, j}$, and $\chi_{x y}^{j, j}$ denote the surface curvatures of $i$, $j$ th subplate, respectively; these surface strains and curvatures are defined as follows:

$$
\begin{aligned}
\varepsilon_{x x, 0}^{i, j} & =\frac{\partial u_{0}^{i, j}}{\partial x}, \\
\varepsilon_{y y, 0}^{i, j} & =\frac{\partial v_{0}^{i, j}}{\partial y}, \\
\gamma_{x y, 0}^{i, j} & =\frac{\partial v_{0}^{i, j}}{\partial x}+\frac{\partial u_{0}^{i, j}}{\partial y}, \\
\gamma_{x z, 0}^{i, j} & =\frac{\partial w_{0}^{i, j}}{\partial x}+\varphi^{i, j}, \\
\gamma_{y z, 0}^{i, j} & =\frac{\partial w_{0}^{i, j}}{\partial y}+\theta^{i, j}, \\
\chi_{x x}^{i, j} & =\frac{\partial \varphi^{i, j}}{\partial x}, \\
\chi_{y y}^{i, j} & =\frac{\partial \theta^{i, j}}{\partial y}, \\
\chi_{x y}^{i, j} & =\frac{\partial \theta^{i, j}}{\partial x}+\frac{\partial \varphi^{i, j}}{\partial y} .
\end{aligned}
$$

Following the state of generalized Hooke's law, the constitutive relations of FG-CNTRC plate can be written as follows:

$$
\left\{\begin{array}{c}
\sigma_{x x}^{i, j} \\
\sigma_{y y}^{i, j} \\
\tau_{y z}^{i, j} \\
\tau_{x z}^{i, j} \\
\tau_{x y}^{i, j}
\end{array}\right\}=\left[\begin{array}{ccccc}
Q_{11}(z) & Q_{12}(z) & 0 & 0 & 0 \\
Q_{12}(z) & Q_{22}(z) & 0 & 0 & 0 \\
0 & 0 & Q_{44}(z) & 0 & 0 \\
0 & 0 & 0 & Q_{55}(z) & 0 \\
0 & 0 & 0 & 0 & Q_{66}(z)
\end{array}\right]\left\{\begin{array}{c}
\varepsilon_{x x}^{i, j} \\
\varepsilon_{y y}^{i, j} \\
\gamma_{y z}^{i, j} \\
\gamma_{x z}^{i, j} \\
\gamma_{x y}^{i, j}
\end{array}\right\},
$$

where $Q_{i j}(i, j=1,2,4,5,6)$ are the reduced material stiffness coefficients compatible with plane-stress conditions and expressed in terms of elastic and shear moduli and Poisson's ratio as 


$$
\begin{aligned}
Q_{11}(z) & =\frac{E_{11}}{1-\mu_{12} \mu_{21}}, \\
Q_{22}(z) & =\frac{E_{22}}{1-\mu_{12} \mu_{21}}, \\
Q_{12}(z) & =\frac{\mu_{21} E_{11}}{1-\mu_{12}}, \\
Q_{44} & =G_{23}, \\
Q_{55} & =G_{13}, \\
Q_{66} & =G_{12},
\end{aligned}
$$

where $G_{13}$ and $G_{23}$ indicate the shear moduli of CNTRC materials. The relationship between the shear moduli is supposed to be $G_{13}=G_{12}, G_{23}=1.2 G_{12}[57,58]$. Through the integration of the stresses and moments of the in-plane stresses across the plate thickness, the force and moment resultants can be expressed as follows:

$$
\begin{aligned}
& \left\{\begin{array}{l}
N_{x x}^{i, j} \\
N_{y y}^{i, j} \\
N_{x y}^{i, j} \\
M_{x x}^{i, j} \\
M_{y y}^{i, j} \\
M_{x y}^{i, j}
\end{array}\right\}=\left[\begin{array}{cccccc}
A_{11} & A_{12} & 0 & B_{11} & B_{12} & 0 \\
A_{12} & A_{22} & 0 & B_{12} & B_{22} & 0 \\
0 & 0 & A_{66} & 0 & 0 & B_{66} \\
B_{11} & B_{12} & 0 & D_{11} & D_{12} & 0 \\
B_{12} & B_{22} & 0 & D_{12} & D_{22} & 0 \\
0 & 0 & B_{66} & 0 & 0 & D_{66}
\end{array}\right]\left\{\begin{array}{c}
\varepsilon_{x x, 0}^{i, j} \\
\varepsilon_{y y, 0}^{i, j} \\
\gamma_{x y, 0}^{i, j} \\
\chi_{x x}^{i, j} \\
\chi_{y y}^{i, j} \\
\chi_{x y}^{i, j}
\end{array}\right\}, \\
& \left\{\begin{array}{c}
Q_{x z}^{i} \\
Q_{y z}^{i}
\end{array}\right\}=\kappa\left[\begin{array}{cc}
A_{55} & 0 \\
0 & A_{44}
\end{array}\right]\left\{\begin{array}{c}
\gamma_{x z}^{0, i} \\
\gamma_{y z}^{0, i}
\end{array}\right\},
\end{aligned}
$$

where $N_{x x}^{i, j}, N_{y y}^{i, j}$, and $N_{x y}^{i, j}$ indicate the in-plane force resultants, $M_{x x}^{i, j}, M_{y y}^{i, j}$, and $M_{x y}^{i, j}$ represent the bending and twisting moment resultants, and $Q_{x z}^{i}$ and $Q_{y z}^{i}$ denote the transverse shear force resultants. In addition, $\kappa=5 / 6$ stands for the shear correction factor, and $A_{i j}, B_{i j}$, and $D_{i j}(i, j=1,2$, $4,5,6)$ represent the stretching, coupling, and bending stiffnesses defined as follows:

$$
\left(A_{i j}, B_{i j}, D_{i j}\right)=\int_{-(h / 2)}^{h / 2} Q_{i j}(z)\left(1, z, z^{2}\right) \mathrm{d} z .
$$

The strain energy of stretching and bending of the FGCNTRC cylindrical shell is expressed as follows. The strain energy $U_{S}^{i, j}$ stored in $i$, $j$ th subplate can be written as

$$
U_{S}^{i, j}=\frac{1}{2} \int_{0}^{a} \int_{0}^{b}\left(N_{x x}^{i, j} \varepsilon_{x x, 0}^{i, j}+N_{y y}^{i, j} \varepsilon_{y y, 0}^{i, j}+N_{x y}^{i} \gamma_{x y, 0}^{i, j}+M_{x x}^{i} \chi_{x x}^{i, j}+M_{y y}^{i, j} \chi_{y y}^{i, j}+M_{x y}^{i, j} \chi_{x y}^{i, j}+Q_{x z}^{i, j} \gamma_{x z}^{i, j}+Q_{y z}^{i, j} \gamma_{y z}^{i, j}\right) \mathrm{d} y \mathrm{~d} x
$$

By substituting equations (6) and (9) into equation (11), the strain energy of the FG-CNTRC plate can be represented using the displacements $\left(u_{0}, v_{0}, w_{0}\right)$ and rotation components $(\varphi, \theta)$.
For the simplification of the equation, equation (11) is represented as $U_{S}^{i, j}=U_{T}^{i, j}+U_{T B}^{i, j}+U_{B}^{i, j}$, where $U_{T}^{i, j}, U_{B}^{i, j}$ and $U_{T B}^{l, j}$ indicate stretching, bending, and bending-stretching coupling energy expressions, respectively. 


$$
\begin{aligned}
& U_{T}^{i, j}=\frac{1}{2} \int_{0}^{a} \int_{0}^{b}\left\{\begin{array}{c}
A_{11}\left(\frac{\partial u_{0}^{i, j}}{\partial x}\right)^{2}+A_{66}\left(\frac{\partial u_{0}^{i, j}}{\partial y}\right)^{2}+2 A_{12} \frac{\partial u_{0}^{i, j}}{\partial x} \frac{\partial v_{0}^{i, j}}{\partial y}+2 A_{66} \frac{\partial u_{0}^{i, j}}{\partial y} \frac{\partial v_{0}^{i, j}}{\partial x} \\
+A_{22}\left(\frac{\partial v_{0}^{i, j}}{\partial y}\right)^{2}+A_{66}\left(\frac{\partial v_{0}^{i, j}}{\partial x}\right)^{2}+\kappa A_{66}\left(\frac{\partial w_{0}^{i, j}}{\partial x}\right)^{2}+\kappa A_{66}\left(\frac{\partial w_{0}^{i, j}}{\partial y}\right)^{2} \\
+2 \kappa A_{66} \frac{\partial w_{0}^{i, j}}{\partial x} \varphi^{i, j}+2 \kappa A_{66} \frac{\partial w_{0}^{i, j}}{\partial y} \theta^{i, j}+\kappa A_{66}\left(\varphi^{i, j}\right)^{2}+\kappa A_{66}\left(\theta^{i, j}\right)^{2}
\end{array}\right\} \mathrm{d} y \mathrm{~d} x, \\
& U_{T B}^{i, j}=\frac{1}{2} \int_{0}^{a} \int_{0}^{b}\left\{\begin{array}{c}
2 B_{11} \frac{\partial u_{0}^{i, j}}{\partial x} \frac{\partial \varphi^{i, j}}{\partial x}+2 B_{12} \frac{\partial u_{0}^{i, j}}{\partial x} \frac{\partial \theta^{i, j}}{\partial y}+2 B_{12} \frac{\partial v_{0}^{i, j}}{\partial y} \frac{\partial \varphi^{i, j}}{\partial x}+2 B_{22} \frac{\partial v_{0}^{i, j}}{\partial y} \frac{\partial \theta^{i, j}}{\partial y} \\
+2 B_{66} \frac{\partial v_{0}^{i, j}}{\partial x} \frac{\partial \theta^{i, j}}{\partial x}+2 B_{66} \frac{\partial v_{0}^{i, j}}{\partial x} \frac{\partial \varphi^{i, j}}{\partial y}+2 B_{66} \frac{\partial u_{0}^{i, j}}{\partial y} \frac{\partial \theta^{i, j}}{\partial x}+2 B_{66} \frac{\partial u_{0}^{i, j}}{\partial y} \frac{\partial \varphi^{i, j}}{\partial y}
\end{array}\right\} \mathrm{d} y \mathrm{~d} x, \\
& U_{B}^{i, j}=\frac{1}{2} \int_{0}^{a} \int_{0}^{b}\left\{\begin{array}{c}
D_{11}\left(\frac{\partial \varphi^{i, j}}{\partial x}\right)^{2}+2 D_{12} \frac{\partial \varphi^{i, j}}{\partial x} \frac{\partial \theta^{i, j}}{\partial y}+2 D_{66} \frac{\partial \varphi^{i, j}}{\partial y} \frac{\partial \theta^{i, j}}{\partial x} \\
+D_{66}\left(\frac{\partial \varphi^{i, j}}{\partial y}\right)^{2}+D_{66}\left(\frac{\partial \theta^{i, j}}{\partial x}\right)^{2}+D_{22}\left(\frac{\partial \theta^{i, j}}{\partial y}\right)^{2}
\end{array}\right\} \mathrm{d} y \mathrm{~d} x
\end{aligned}
$$

The kinetic energy of a certain segment could be obtained as follows:

$$
\begin{aligned}
T & =\frac{1}{2} \iint_{A} \rho\left[\left(\dot{u}_{0}^{i, j}+z \dot{\varphi}^{i, j}\right)^{2}+\left(\dot{v}_{0}^{i, j}+z \dot{\theta}^{i, j}\right)^{2}+\left(\dot{w}_{0}^{i, j}\right)^{2}\right] \mathrm{d} A \\
& =\frac{1}{2} \iint_{A} \int_{-(h / 2)}^{h / 2} \rho\left[\left(\dot{u}_{0}^{i, j}\right)^{2}+2 \dot{u}_{0}^{i, j} \dot{\varphi}^{i, j} z+z^{2}\left(\dot{\varphi}^{i, j}\right)^{2}+\left(\dot{v}_{0}^{i, j}\right)^{2}+2 \dot{v}_{0}^{i, j} \dot{\theta}^{i, j} z+z^{2}\left(\dot{\theta}^{i, j}\right)^{2}+\left(\dot{w}_{0}^{i, j}\right)^{2}\right] \mathrm{d} z \mathrm{~d} A \\
& =\frac{1}{2} \iint_{A}\left\{I_{0}\left[\left(\dot{u}_{0}^{i, j}\right)^{2}+\left(\dot{v}_{0}^{i, j}\right)^{2}+\left(\dot{w}_{0}^{i, j}\right)^{2}\right]+2 I_{1}\left(\dot{u}_{0}^{i, j} \dot{\varphi}^{i, j}+\dot{v}_{0}^{i, j} \dot{\theta}^{i, j}\right)+I_{2}\left[\left(\dot{\varphi}^{i, j}\right)^{2}+\left(\dot{\theta}^{i, j}\right)^{2}\right]\right\} \mathrm{d} A .
\end{aligned}
$$

The dots on the symbols indicate the differentiation of displacement components with respect to time.

$$
\left(I_{0}, I_{1}, I_{2}\right)=\int_{-(h / 2)}^{h / 2} \rho(z)\left(1, z, z^{2}\right) \mathrm{d} z .
$$

$$
\begin{aligned}
U_{b}= & \frac{1}{2} \int_{0}^{b}\left\{\left[k_{u, x 0} u_{0}^{2}+k_{v, x 0} v_{0}^{2}+k_{w, x 0} w_{0}^{2}+k_{\varphi, x 0} \varphi_{0}^{2}+k_{\theta, x 0} \theta_{0}^{2}\right]_{x=0}+\left[k_{u, x 1} u_{0}^{2}+k_{v, x 1} v_{0}^{2}+k_{w, x 1} w_{0}^{2}+k_{\varphi, x 1} \varphi_{0}^{2}+k_{\theta, x 1} \theta_{0}^{2}\right]_{x=L}\right\} \mathrm{d} y \\
& +\frac{1}{2} \int_{0}^{a}\left\{\left[k_{u, y 0} u_{0}^{2}+k_{v, y 0} v_{0}^{2}+k_{w, y 0} w_{0}^{2}+k_{\varphi, y 0} \varphi_{0}^{2}+k_{\theta, y 0} \theta_{0}^{2}\right]_{y=0}+\left[k_{u, y 1} u_{0}^{2}+k_{v, y 1} v_{0}^{2}+k_{w, y 1} w_{0}^{2}+k_{\varphi, y 1} \varphi_{0}^{2}+k_{\theta, y 1} \theta_{0}^{2}\right]_{y=L}\right\} \mathrm{d} x,
\end{aligned}
$$

The potential energy stored in the boundary springs is expressed as follows: 
where $k_{t, 0}(t=u, v, w, \varphi, \theta)$ and $k_{t, 1}$ represent the boundary spring stiffness of the both ends of FG-CNTRC plate, respectively.
The potential energy stored in the connective springs is represented as follows:

$$
\begin{aligned}
U_{c}^{i, j}= & \frac{1}{2} \int_{0}^{b}\left\{k_{u}\left(u_{0}^{i}-u_{0}^{i+1}\right)^{2}+k_{v}\left(v_{0}^{i}-v_{i+1}\right)^{2}+k_{w}\left(w_{0}^{i}-w_{i+1}\right)^{2}+k_{\varphi}\left(\varphi^{i}-\varphi_{i+1}\right)^{2}+k_{\theta}\left(\theta^{i}-\theta_{i+1}\right)^{2}\right\} \mathrm{d} y \\
& +\frac{1}{2} \int_{0}^{a}\left\{k_{u}\left(u^{j}-u^{j+1}\right)^{2}+k_{v}\left(v^{j}-v^{j+1}\right)^{2}+k_{w}\left(w^{j}-w^{j+1}\right)^{2}+k_{\varphi}\left(\varphi^{j}-\varphi^{j+1}\right)^{2}+k_{\theta}\left(\theta^{j}-\theta^{j+1}\right)^{2}\right\} \mathrm{d} x,
\end{aligned}
$$

where $k_{u}, k_{v}, k_{w}, k_{\varphi}$, and $k_{\theta}$ represent the stiffnesses of the springs between individual subplates and the superscripts $i$ and $i+1$ denote the $i$ th and $i+1$ th subplates.

Therefore, total potential energy including boundary conditions and connective conditions can be represented as follows:

$$
U=\sum_{i=1}^{N_{x}} \sum_{j=1}^{N_{y}} U_{s}^{i, j}+\sum_{i=1}^{N_{x}-1} \sum_{j=1}^{N_{y}-1} U_{c}^{i, j}+U_{b} .
$$

As a result, the arbitrary boundary conditions can be freely modeled in the proposed model by setting the stiffness of the springs as proper values.

It is supposed that the external force act on the entire middle surface of the FG-CNTRC plate. The virtual work done on the $i$, $j$ th subplate by the distributed load components can be expressed as follows [59]:

$$
W^{i, j}=\frac{1}{2} \iiint_{V}\left(f_{u}^{i, j} u_{0}^{i, j}+f_{v}^{i, j} v_{0}^{i, j}+f_{w}^{i, j} w_{0}^{i, j}+m_{\varphi}^{i, j} \varphi_{0}^{i, j}+m_{\theta}^{i, j} \theta_{0}^{i, j}\right) \mathrm{d} V
$$

2.4. Solution Procedure. The convergence and accuracy of the analysis results rely on the selection of the displacement. In this research, the vibration characteristics of FG-CNTRC plate are studied using the suitable allowable displacement function. Finally, all the displacement functions including boundary and continuous conditions are chosen as ultraspherical polynomials. The ultraspherical polynomial is a special case of the Jacobi orthogonal polynomial, and main advantage is that it can guarantee the very high accuracy and robustness of computation [60-62]. When the polynomial's parameter $\lambda=0$, the ultraspherical polynomials $P_{m}^{(\lambda)}(\xi)$ are called as first kind of Chebyshev polynomials $\left(C_{m}(\xi)\right)$, while they are represented as Legendre polynomials $L_{m}(\xi)$ if $\lambda=0.5$. When $\lambda=1, P_{m}^{(\lambda)}(\xi)$ is indicated as second kind of Chebyshev polynomials. The ultraspherical polynomials $P_{m}^{(\lambda)}(\xi)$ are defined in the interval $\xi \in[-1,1]$.

$$
\mathfrak{J}(\xi)=\left(1-\xi^{2}\right)^{\lambda-(1 / 2)}, \quad \lambda>-\frac{1}{2} .
$$

The orthogonality condition is

$$
\int_{-1}^{1}\left(1-\xi^{2}\right)^{\lambda-(1 / 2)} P_{m}^{(\lambda)}(\xi) P_{n}^{(\lambda)}(\xi) \mathrm{d} x= \begin{cases}\frac{\sqrt{\pi} n ! \Gamma(2 \lambda) \Gamma(\lambda+(1 / 2))}{\Gamma(n+2 \lambda)(n+\lambda) \Gamma(\lambda)}, & m=n, \\ 0, & m \neq n .\end{cases}
$$

The ultraspherical polynomials $P_{m}^{(\lambda)}(\xi)$ can be also expressed with the recurrence relation $[63,64]$.

$$
(m+2 \lambda) P_{m}^{(\lambda)}(\xi)=2(m+\lambda) \xi P_{m}^{(\lambda)}(\xi)-m P_{m-1}^{(\lambda)}(\xi),
$$

where $m=1,2,3, \ldots$ 
Therefore, the allowable displacement function of FGCNTRC plate can be more generalized using the ultraspherical polynomials and written as

$$
\begin{aligned}
& u=\sum_{m_{x}=0}^{M_{x}} \sum_{n_{y}=0}^{N_{y}} U_{m n} P_{m_{x}}^{(\lambda)}\left(\xi_{x}\right) P_{n_{y}}^{(\lambda)}\left(\xi_{y}\right) e^{i \omega t}, \\
& v=\sum_{m_{x}=0}^{M_{x}} \sum_{n_{y}=0}^{N_{y}} V_{m n} P_{m_{x}}^{(\lambda)}\left(\xi_{x}\right) P_{n_{y}}^{(\lambda)}\left(\xi_{y}\right) e^{i \omega t}, \\
& w=\sum_{m_{x}=0}^{M_{x}} \sum_{n_{y}=0}^{N_{y}} W_{m n} P_{m_{x}}^{(\lambda)}\left(\xi_{x}\right) P_{n_{y}}^{(\lambda)}\left(\xi_{y}\right) e^{i \omega t}, \\
& \varphi=\sum_{m_{x}=0}^{M_{x}} \sum_{n_{y}=0}^{N_{y}} \Phi_{m n} P_{m_{x}}^{(\lambda)}\left(\xi_{x}\right) P_{n_{y}}^{(\lambda)}\left(\xi_{y}\right) e^{i \omega t}, \\
& \theta=\sum_{m_{x}=0}^{M_{x}} \sum_{n_{y}=0}^{N_{y}} \Theta_{m n} P_{m_{x}}^{(\lambda)}\left(\xi_{x}\right) P_{n_{y}}^{(\lambda)}\left(\xi_{y}\right) e^{i \omega t,}
\end{aligned}
$$

where $U_{m n}, V_{m n}, W_{m n}, \Phi_{m n}$, and $\Theta_{m n}$ indicate the unknown coefficients of the ultraspherical polynomials and $M_{x}, N_{y}$ are maximum $m$-order and $n$-order, respectively. $P_{m}^{(\lambda)}\left(\xi_{x}\right)$, $P_{n}^{(\lambda)}\left(\xi_{y}\right)$ denote the $m$-order and $n$-order ultraspherical polynomials in regard to displacement in $x$ and $y$ directions, and $\omega, t$ represent the angular frequency and time, respectively. As the ultraspherical polynomials are complete and the orthogonal polynomials are defined at interval of $\xi \in[-1,1]$, the linear transformation statute should be applied for the coordinate conversion from the interval $x \in[0$, $L]$ of the divided beam to the interval $\xi(\xi \in[-1,1])$ of the ultraspherical polynomials, that is, $\xi=2 x / L-1$.

The total Lagrangian energy functions of FG-CNTRC plate can be written as follows:

$$
\mathbf{L}=\sum_{i=1}^{N_{x}} \sum_{i=1}^{N_{y}}\left(T^{i, j}-U^{i, j}\right)+W^{i, j} .
$$

The total Lagrangian energy function can be minimized in regard to the unknown coefficients based on the Rayleigh-Ritz method.

$$
\frac{\partial \mathbf{L}}{\partial I}=0, \quad I=U_{m}, V_{m}, W_{m}, \Phi_{m}, \Theta_{m} .
$$

Therefore, the vibration governing equation of FGCNTRC plate can be indicated as follows:

$$
\left(\mathbf{K}-\omega^{2} \mathbf{M}\right) \mathbf{A}=\mathbf{F} .
$$

The stiffness matrix $\mathbf{K}$, mass matrix $\mathbf{M}$, and unknown coefficient matrix $\mathbf{A}$ are represented by the following equations. The natural frequencies of the FG-CNTRC plate can be calculated when the right term $\mathbf{F}$ in equation (25) equals zero. The detailed expression of stiffness matrix $\mathbf{K}$ and mass matrix $\mathbf{M}$ in equation (25) can be found in the Appendix.

\section{Convergence and Validation Study}

To ensure the validity and accuracy of the suggested method, the calculation examples for the free and forced vibration analysis of FG-CNTRC under the several boundary conditions are presented. The calculation results from the suggested method are compared with those of the previous works or obtained by the finite element analysis software ABAQUS. Based on the validation results, the effects of geometric and material parameters on the free or forced vibration response are studied. MATLAB is applied for the calculation process of the proposed method, which is run on a Intel(R) Core(TM) i7-7500 2.20 GHz PC.

3.1. Convergence Study. As can be seen from the theoretical formula, the accuracy of the solution calculated by the proposed method is determined by the degree of the ultraspherical polynomial and polynomial parameters. Therefore, it is necessary to conduct the convergence study to determine these parameters. It is certain that the accuracy of solution becomes higher as the degree of polynomial increases infinitely. However, in this case, as it requires high level of hardware and increased amount of calculation time, it is important to determine the reasonable degree of polynomial. For the convergence study, it is supposed that the material has the characteristics of uniform distribution and the material and geometric properties are set as follows:

$$
\begin{aligned}
E^{m} & =3 \mathrm{GPa}, \\
\rho^{m} & =1000 \mathrm{~kg} / \mathrm{m}^{3}, \\
\mu^{m} & =0.3, \\
E_{11}^{\mathrm{CNT}} & =5 \mathrm{TPa}, \\
E_{22}^{\mathrm{CNT}} & =7 \mathrm{TPa}, \\
G_{12}^{\mathrm{CNT}} & =2 \mathrm{TPa}, \\
\rho^{\mathrm{CNT}} & =1500 \mathrm{~kg} / \mathrm{m}^{3}, \\
\mu_{12}^{\mathrm{CNT}} & =0.2, \\
V_{\mathrm{CNT}}^{*} & =0.1, \\
\eta_{1} & =0.1, \\
\eta_{2} & =1, \\
\eta_{3} & =0.7, \\
a & =1 \mathrm{~m}, \\
b & =1 \mathrm{~m}, \\
h & =0.05 \mathrm{~m} .
\end{aligned}
$$

Also, in all the following processes, the dimensionless frequency is calculated by the formula $\Omega=\left(\omega a_{1}^{2} / h_{1}\right.$ $\left.\sqrt{\rho^{m} / E^{m}}\right)$.

Table 1 shows the convergence characteristics of nondimensional frequency of the FG-CNTRC plates, in which four sides are fully clamped, according to the increase of ultraspherical polynomial degree $M x \times N y$. From Table 1, it can be known that as the degree of polynomial increases, the dimensionless frequency of FG-CNTRC plates approximate to a certain value, and then it does not change any more after the degree of polynomial is beyond $M x \times N y=10 \times 10$. Therefore, in this research, in all the calculation of the numerical examples, the degree of $M x \times N y$ is set as $M x \times N y=10 \times 10$. In addition, the 
TABLE 1: Convergence of dimensionless frequencies of stepped FG-CNTRC plate.

\begin{tabular}{|c|c|c|c|c|c|c|c|c|c|c|c|}
\hline \multirow[b]{2}{*}{ Truncated number } & \multicolumn{11}{|c|}{ Mode } \\
\hline & 1 & 2 & 3 & 4 & 5 & $\begin{array}{c}6 \\
\text { Present }\end{array}$ & 7 & 8 & 9 & 10 & Time (s) \\
\hline $3 \times 3$ & 6.6971 & 11.128 & 13.265 & 16.000 & 18.294 & 23.371 & 26.201 & 26.572 & 28.040 & 28.605 & 0.544 \\
\hline $4 \times 4$ & 5.3525 & 7.3636 & 11.755 & 12.918 & 15.009 & 18.220 & 18.434 & 20.143 & 20.892 & 22.72 & 0.542 \\
\hline $5 \times 5$ & 5.3382 & 6.8156 & 10.035 & 11.476 & 12.358 & 14.533 & 16.898 & 18.218 & 18.868 & 19.487 & 0.548 \\
\hline $6 \times 6$ & 5.3379 & 6.8133 & 9.9013 & 11.473 & 12.354 & 14.344 & 14.434 & 17.909 & 18.217 & 18.770 & 0.555 \\
\hline $7 \times 7$ & 5.3378 & 6.8121 & 9.8712 & 11.472 & 12.353 & 14.274 & 14.415 & 17.857 & 18.217 & 18.760 & 0.563 \\
\hline $8 \times 8$ & 5.3378 & 6.8121 & 9.8707 & 11.472 & 12.353 & 14.238 & 14.415 & 17.829 & 18.217 & 18.760 & 0.568 \\
\hline $9 \times 9$ & 5.3377 & 6.8121 & 9.8704 & 11.472 & 12.353 & 14.237 & 14.415 & 17.829 & 18.217 & 18.760 & 0.590 \\
\hline $10 \times 10$ & 5.3379 & 6.8120 & 9.8704 & 11.472 & 12.353 & 14.237 & 14.415 & 17.828 & 18.217 & 18.760 & 0.770 \\
\hline $11 \times 11$ & 5.3378 & 6.8120 & 9.8704 & 11.472 & 12.353 & 14.237 & 14.415 & 17.828 & 18.217 & 18.760 & 0.829 \\
\hline $12 \times 12$ & 5.3378 & 6.8120 & 9.8704 & 11.472 & 12.353 & 14.237 & 14.414 & 17.828 & 18.217 & 18.760 & 1.007 \\
\hline $13 \times 13$ & 5.3378 & 6.8120 & 9.8704 & 11.472 & 12.353 & 14.237 & 14.414 & 17.828 & 18.217 & 18.760 & 1.158 \\
\hline Number of element & \multicolumn{11}{|c|}{ FEM (ABAQUS) } \\
\hline 1600 & 5.3429 & 6.8255 & 9.9275 & 11.499 & 12.376 & 14.395 & 14.458 & 17.946 & 18.230 & 18.836 & 1.3 \\
\hline 2500 & 5.3411 & 6.8206 & 9.9068 & 11.489 & 12.368 & 14.338 & 14.442 & 17.904 & 18.227 & 18.809 & 1.9 \\
\hline 10000 & 5.3387 & 6.8142 & 9.8794 & 11.476 & 12.356 & 14.262 & 14.421 & 17.847 & 18.219 & 18.772 & 6.7 \\
\hline 22500 & 5.3381 & 6.8130 & 9.8745 & 11.474 & 12.354 & 14.248 & 14.417 & 17.836 & 18.217 & 18.765 & 14.5 \\
\hline 40000 & 5.3380 & 6.8126 & 9.8726 & 11.473 & 12.353 & 14.243 & 14.416 & 17.832 & 18.217 & 18.763 & 30.3 \\
\hline
\end{tabular}

calculation time by the method proposed in Table 1 and the calculation time by FEM (ABAQUS) are shown. As shown in Table 1, when the number of elements is 40000 , it is the most similar to the result of the proposed method, and the calculation time required at this time is $30.3 \mathrm{~s}$. In the case of the proposed method, the calculation time is $0.77 \mathrm{~s}$ (in the case of $M x \times N y=10 \times 10$ ), and it can be seen that the calculation time is much shorter than that of the FEM. In other words, it can be seen that the proposed method has the advantage of very high calculation accuracy and calculation efficiency.

As mentioned above, as the ultraspherical polynomial is characterized by the polynomial's parameter $\lambda$, it is necessary to conduct the study on the determination of polynomial parameters. Figure 4 presents the percentage error $\left(\Omega_{\lambda}-\Omega_{\lambda=0}\right) / \Omega_{\lambda=} 0$ of the solution of the ultraspherical polynomial parameter $\lambda$ in the FG-CNTRC plate. Figure 4 indicates that the error of dimensionless frequency in the FG-CNTRC plate does not exceed $1.5 \times 10^{-4}$ regardless of the change of polynomial parameter $\lambda$. Therefore, in this research, the polynomial parameter $\lambda$ is set as 0 .

As mentioned in the previous section, the artificial elastic spring technique is introduced to generalize the boundary conditions for the vibration analysis of the stepped FGCNTRC plate. The boundary condition is changed according to the selection of the stiffness of artificial elastic spring. Therefore, it is necessary to conduct the determination study of the boundary conditions.

Figure 5 shows the variation characteristics of the nondimensional frequency in the FG-CNTRC plate according to the change of stiffness of the boundary elastic spring. In order to analyze the variation characteristics of the FGCNTRC plate according to the change of stiffness of the individual boundary spring, except for the considered boundary spring, the stiffness of all other boundary springs is set as zero, and then the stiffness of the considered spring is changed from $10^{2}$ to $10^{16}$. As can be seen from Figure 5, the frequency shows almost no change when the stiffness of boundary spring is below $10^{4}$, and then it increases dramatically beyond this value until the stiffness reaches $10^{11}$. When the stiffness is beyond $10^{11}$, the frequency does not change again. Based on these results, the classic and elastic boundary conditions for the calculation of vibration characteristics in the FG-CNTRC plate can be set as shown in Table 2. In Table 2, F, S, C, and E indicate the free, simple, clamped, and elastic boundary conditions. In addition, in the following processes, the boundary condition $\mathrm{CFSE}_{1}$ represents the clamped boundary condition at $x=0$, free boundary condition at $x=a$, simple-supported boundary condition at $y=0$, and elastic boundary condition at $y=b$, respectively.

\subsection{Validation}

3.2.1. Free Vibration. In the previous section, through the convergence study, parameters including the boundary parameter for the vibration analysis of multi-stepped FGCNTRC plates are determined. Based on these results, the accuracy of the suggested method is validated. The accuracy is validated by comparing the results from the proposed method with those from the previous works or finite element method. Table 3 shows the comparison results of the dimensionless frequency of the non-stepped plates with isotropic materials. Here, Poisson's ratio is 0.3. Table 3 indicates that the results from the proposed method agree well with those of the previous works.

Next, the natural frequency result of stepped plates with isotropic materials is compared with that obtained by the finite element method. The stepped plate consists of three subplates in $x$ and $y$ directions, respectively, and the geometric parameters are $a_{1}=0.5 \mathrm{~m}, a_{2}=0.1 \mathrm{~m}, a_{3}=0.5 \mathrm{~m}$, $b_{1}=0.5 \mathrm{~m}, b_{2}=0.1 \mathrm{~m}, b_{3}=0.5 \mathrm{~m}, h_{x 1}=0.1 \mathrm{~m}, h_{x 2}=0.2 \mathrm{~m}$, 


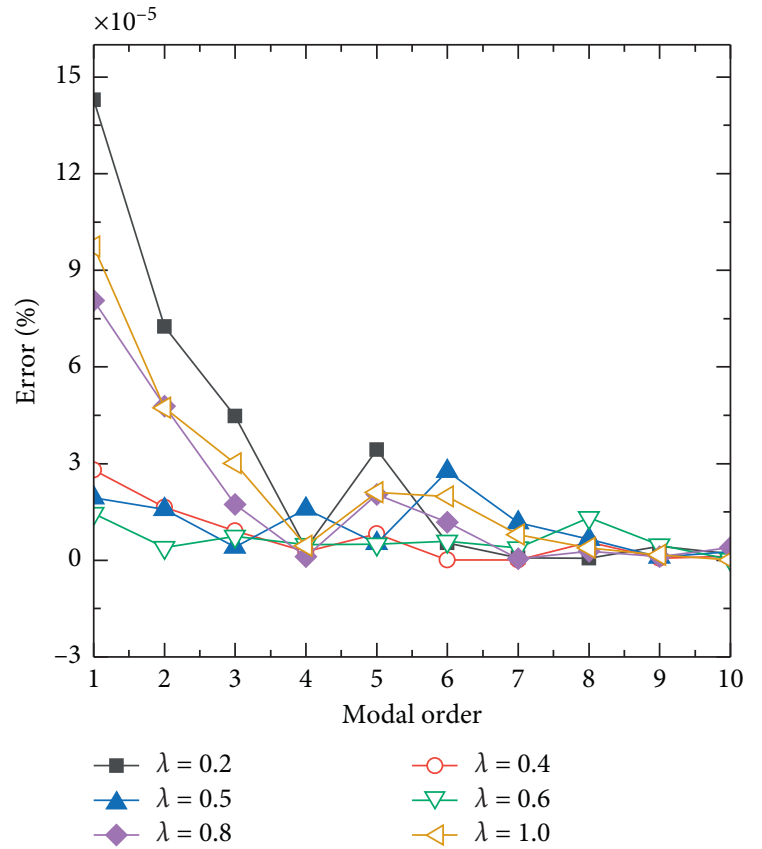

(a)

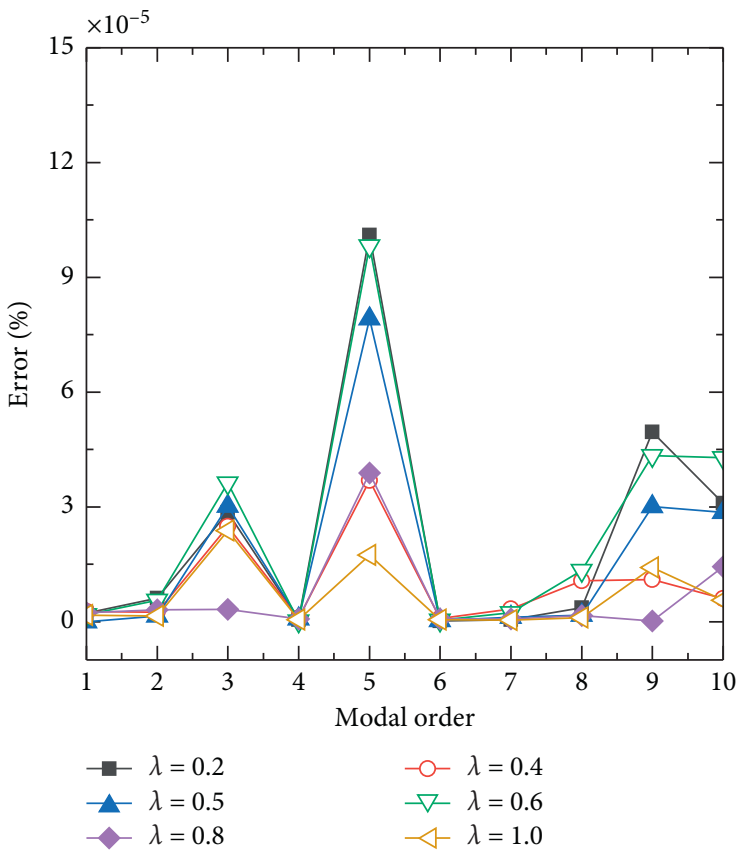

(b)

FIgURE 4: Percentage error of the dimensionless frequencies for the ultraspherical polynomial parameters $\lambda$. (a) CCCC. (b) FFFF.

$h_{x 3}=0.1 \mathrm{~m}, h_{y 1}=0.1 \mathrm{~m}, h_{y 2}=0.2 \mathrm{~m}$, and $h_{y 3}=0.1 \mathrm{~m}$. The finite element analysis software ABAQUS is used in the finite element method, and the element type is S4R and the number of elements is 8476 .

Through the comparison results of Tables 3 and 4 , it can be known that the suggested method is suitable for the free vibration analysis of non-stepped or stepped plates. The main purpose of this research is to study the vibration analysis method of the multi-stepped FG-CNTRC plate; therefore, the accuracy of the proposed method is validated by comparing the results of natural frequency in the FGCNTRC plate using the suggested method. Table 5 shows the comparison results of natural frequency in the non-stepped FG-CNTRC plate. The material and geometric parameters are as follows [16]:

$$
\begin{aligned}
E^{m} & =2.1 \mathrm{GPa}, \\
\rho^{m} & =1150 \mathrm{~kg} / \mathrm{m}^{3}, \\
\mu^{m} & =0.34, \\
E_{11}^{\mathrm{CNT}} & =5.6466 \mathrm{TPa}, \\
E_{22}^{\mathrm{CNT}} & =7.08 \mathrm{TPa}, \\
G_{12}^{\mathrm{CNT}} & =1.9445 \mathrm{TPa}, \\
V_{\mathrm{CNT}}^{*} & =0.11, \\
\eta_{1} & =0.149, \\
\eta_{2} & =0.934, \\
\eta_{3} & =0.934, \\
a & =1 \mathrm{~m}, \\
b & =1 \mathrm{~m} .
\end{aligned}
$$

As can be seen from Table 5, the dimensionless frequency in the non-stepped FG-CNTRC plate with uniform thickness agrees well with the previous works.

Next, the natural frequency results of the multi-stepped FG-CNTRC plate are compared with that obtained by the finite element method. The material properties are the same as the case mentioned above, and the geometric properties and the parameters for the finite element analysis are set as shown in Table 3. Tables 5 and 6 show that the results from the proposed method agree well with those of the previous works or obtained by the finite element method, and through the convergence and validity study, it can be known that the suggested method is the accurate method for the free vibration analysis for not only the isotropic materials but also the non-stepped and multi-stepped plates of FGCNTRC. The finite element analysis software ABAQUS is used in the finite element method, and the element type is S4R and the number of elements is 10868 .

3.2.2. Forced Vibration. In engineering applications, the external loads act on the plate which is the foundation construction, so it is needed to consider the forced response of structures. Considering the forced response, there mainly exist two parts such as the stability response analysis in frequency domain and transient response analysis in time domain. In this section, the accuracy of the proposed method is validated by comparing the forced vibration results obtained by the proposed method with those from the finite element method. For the analysis of the forced vibration, in the following research processes, the external forces are considered as three cases such as point force, line force, and area force, and it is assumed that the uniform load $\left(f_{w}=1 \mathrm{~N}\right)$ is applied in the $Z$ direction $[63,69]$. 


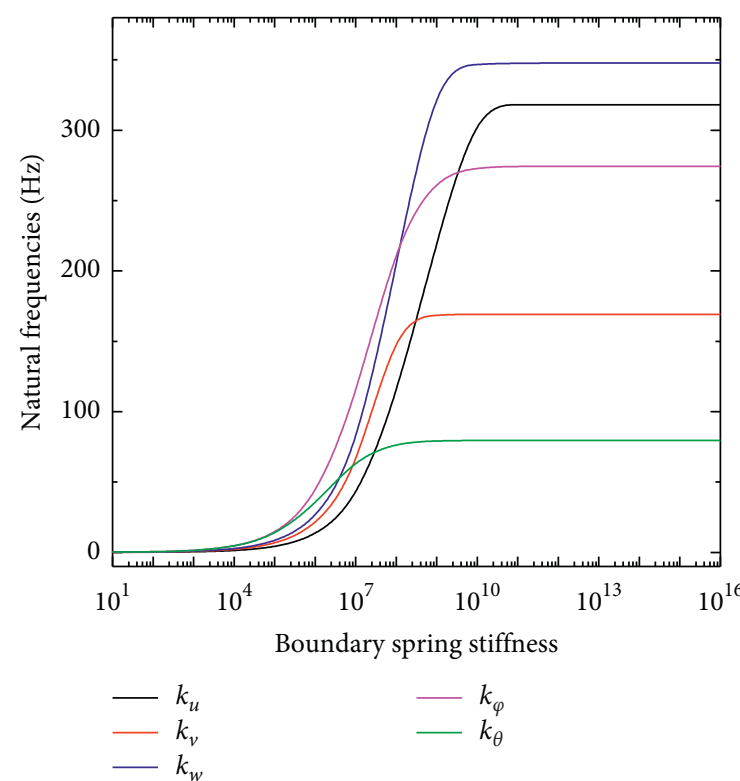

(a)

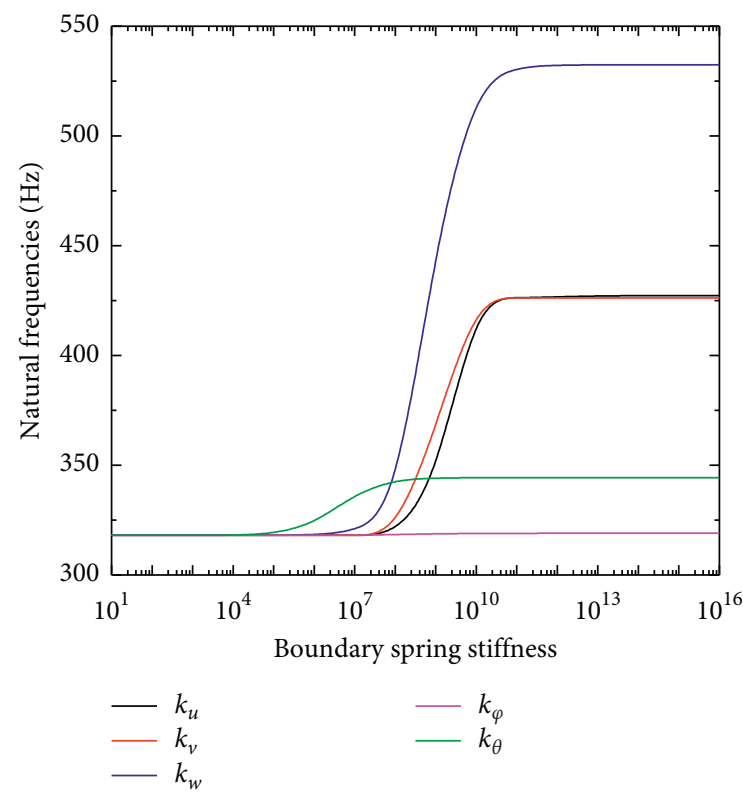

(c)
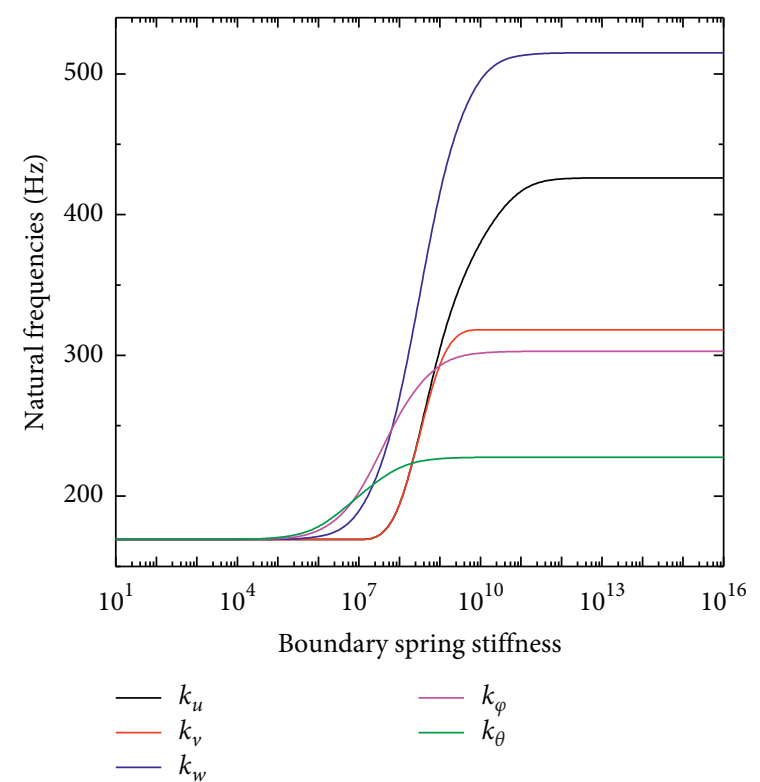

(b)

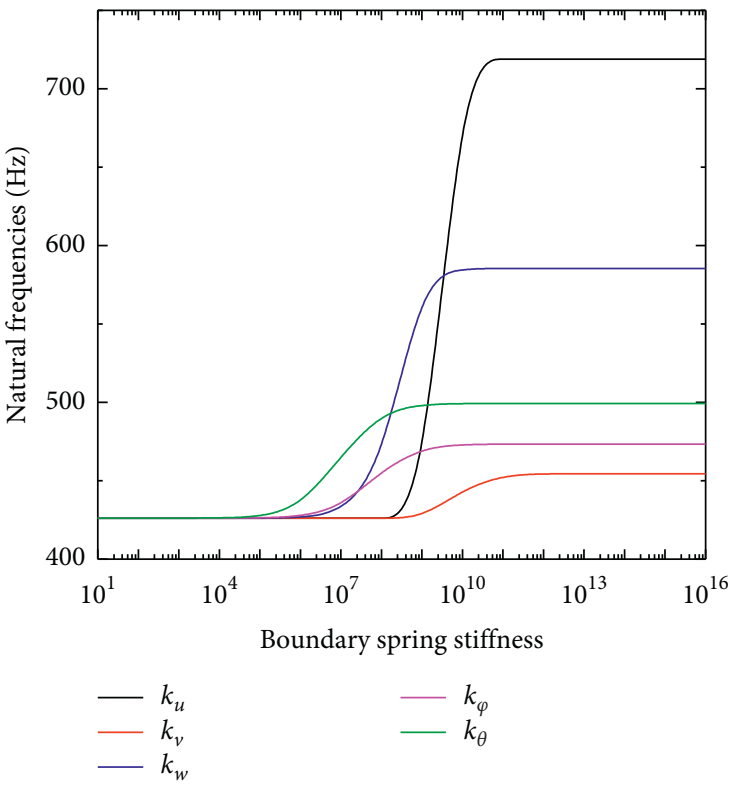

(d)

FiguRE 5: Convergence characteristics of dimensionless frequencies on the boundary spring stiffness. (a) Mode1. (b) Mode2. (c) Mode3. (d) Mode4.

Figure 6 represents the comparison results between steady-state responses in the non-stepped and multi-stepped FG-CNTRC plate under the CCCC boundary condition. The geometric and material parameters are the same as those shown in Tables 5 and 6 . The ranges of natural frequency are from 300 to 900 in the non-stepped plates and from 300 to 800 in the multi-stepped plates, respectively. The interval is set as $1 \mathrm{~Hz}$. Here, the harmonic point force $f_{w}$ acts in the thickness direction. The point load is $f_{w}=\bar{f}_{w}$ $\delta\left(x-l x_{1}\right)\left(y-l x_{1}\right)$, in which $\vec{f}_{w}=-1 \mathrm{~N}$ and $\delta$ indicates the Dirac delta function. The applied point of force and response measurement point are all set as $A=(0.3 \mathrm{~m}, 0.3 \mathrm{~m})$ and $B=(0.3 \mathrm{~m}, 0.3 \mathrm{~m})$. The comparison is made with the data obtained from the finite element analysis software ABAQUS, and the calculation is conducted under the same conditions.

The comparison results in Figure 6 indicate that the proposed method is suitable for the steady-state vibration analysis of multi-stepped FG-CNTRC plate.

Next, the comparison study for the transient response analysis is conducted. In this case, it is supposed that four kinds of transient loads are applied. Figure 7 shows four types of transient loads used in this paper. 
TABLE 2: The spring stiffness values of the elastic boundary conditions.

\begin{tabular}{|c|c|c|c|c|c|}
\hline Boundary conditions & $k_{u, 0}, k_{u, 1}$ & $k_{v, 0}, k_{v, 1}$ & $k_{w, 0}, k_{w, 1}$ & $k_{\varphi, 0}, k_{\varphi, 1}$ & $k_{\theta, 0}, k_{\theta, 1}$ \\
\hline $\mathrm{F}$ & 0 & 0 & 0 & 0 & 0 \\
\hline S & 0 & $10^{14}$ & $10^{14}$ & 0 & $10^{14}$ \\
\hline $\mathrm{C}$ & $10^{14}$ & $10^{14}$ & $10^{14}$ & $10^{14}$ & $10^{14}$ \\
\hline $\mathrm{E}_{1}$ & $10^{8}$ & $10^{6}$ & $10^{6}$ & $10^{14}$ & $10^{14}$ \\
\hline $\mathrm{E}_{2}$ & $10^{14}$ & $10^{14}$ & $10^{14}$ & $10^{8}$ & $10^{8}$ \\
\hline $\mathrm{E}_{3}$ & $10^{8}$ & $10^{8}$ & $10^{8}$ & $10^{8}$ & $10^{8}$ \\
\hline
\end{tabular}

TABle 3: Comparison of dimensionless frequencies of non-stepped isotropic plate.

\begin{tabular}{|c|c|c|c|c|c|c|c|c|c|}
\hline \multirow{2}{*}{ Boundary conditions } & \multirow{2}{*}{$h$} & \multirow{2}{*}{ Refs. } & \multicolumn{7}{|c|}{ Modes } \\
\hline & & & 1 & 2 & 3 & 4 & 5 & 6 & 7 \\
\hline \multirow{8}{*}{ SSSS } & \multirow{4}{*}{0.1} & Present & 19.065 & 45.482 & 45.482 & 64.368 & 64.368 & 69.793 & 85.523 \\
\hline & & Reference [65] & 19.098 & 45.636 & 45.636 & 64.384 & 64.384 & 70.149 & 85.5 \\
\hline & & Reference [66] & 19.09 & 45.622 & 45.622 & 64.383 & 64.383 & 70.112 & 85.502 \\
\hline & & Reference [67] & 19.09 & 45.619 & 45.619 & 64.383 & 64.383 & 70.104 & 85.488 \\
\hline & \multirow{4}{*}{0.2} & Present & 17.448 & 32.176 & 32.176 & 38.149 & 38.149 & 45.526 & 55.144 \\
\hline & & Reference [65] & 17.528 & 32.192 & 32.192 & 38.488 & 38.488 & 45.526 & 55.802 \\
\hline & & Reference [66] & 17.528 & 32.192 & 32.192 & 38.502 & 38.502 & 45.526 & 55.843 \\
\hline & & Reference [67] & 17.526 & 32.192 & 32.192 & 38.483 & 38.483 & 45.526 & 55.787 \\
\hline \multirow{8}{*}{ CCСC } & \multirow{4}{*}{0.1} & Present & 32.53 & 62.051 & 62.051 & 86.963 & 103.89 & 104.94 & 123.11 \\
\hline & & Reference [65] & 33.009 & 63.043 & 63.043 & 88.411 & 104.28 & 105.29 & 123.73 \\
\hline & & Reference [66] & 32.797 & 62.672 & 62.672 & 87.941 & 103.71 & 104.7 & 123.6 \\
\hline & & Reference [67] & 32.782 & 62.63 & 62.63 & 87.869 & 103.61 & 104.6 & 123.59 \\
\hline & \multirow{4}{*}{0.2} & Present & 26.522 & 46.29 & 46.29 & 61.531 & 61.531 & 63.756 & 71.962 \\
\hline & & Reference [65] & 27.065 & 47.346 & 47.346 & 62.00 & 62 & 63.635 & 72.604 \\
\hline & & Reference [66] & 26.974 & 47.253 & 47.253 & 61.944 & 61.944 & 63.57 & 72.568 \\
\hline & & Reference [67] & 26.906 & 47.103 & 47.103 & 61.917 & 61.917 & 63.348 & 72.286 \\
\hline \multirow{6}{*}{ FFFF } & \multirow{3}{*}{0.1} & Present & 12.734 & 18.945 & 23.328 & 31.994 & 31.994 & 55.377 & 55.377 \\
\hline & & Reference [65] & 12.728 & 18.956 & 23.346 & 31.965 & 31.965 & 55.493 & 55.493 \\
\hline & & Reference [68] & 12.726 & 18.955 & 23.347 & 31.965 & 31.965 & 55.493 & 55.493 \\
\hline & \multirow{3}{*}{0.2} & Present & 11.702 & 17.4 & 21.194 & 27.58 & 27.58 & 40.194 & 42.81 \\
\hline & & Reference [65] & 11.71 & 17.433 & 21.252 & 27.648 & 27.648 & 40.192 & 42.775 \\
\hline & & Reference [68] & 11.71 & 17.433 & 21.252 & 27.647 & 27.647 & 40.191 & 42.776 \\
\hline
\end{tabular}

TABLE 4: Comparison of natural frequency of non-stepped isotropic plate.

\begin{tabular}{|c|c|c|c|c|c|c|c|c|c|}
\hline \multirow{3}{*}{ Frequency } & \multicolumn{9}{|c|}{ Boundary conditions } \\
\hline & \multicolumn{3}{|c|}{ CCCC } & \multicolumn{3}{|c|}{ SSSS } & \multicolumn{3}{|c|}{ CCFF } \\
\hline & Present & FEM & Error $(\%)$ & Present & FEM & Error $(\%)$ & Present & FEM & Error $(\%)$ \\
\hline 1 & 812.7764 & 813.05 & 0.0337 & 439.6185 & 439.62 & 0.0003 & 467.8344 & 468.13 & 0.0632 \\
\hline 2 & 1513.904 & 1516.1 & 0.1451 & 1100.106 & 1101.4 & 0.1176 & 488.3953 & 488.53 & 0.0276 \\
\hline 3 & 1513.954 & 1516.1 & 0.1418 & 1100.115 & 1101.4 & 0.1168 & 909.7355 & 909.7 & 0.0039 \\
\hline 4 & 1998.549 & 1999.9 & 0.0676 & 1551.629 & 1552.6 & 0.0626 & 1190.218 & 1192.4 & 0.1834 \\
\hline 5 & 2479.551 & 2486.7 & 0.2883 & 2028.033 & 2032.9 & 0.24 & 1232.625 & 1234 & 0.1115 \\
\hline 6 & 2485.876 & 2493 & 0.2866 & 2043.13 & 2048.4 & 0.2579 & 1263.875 & 1265.4 & 0.1207 \\
\hline 7 & 2603.5 & 2605.8 & 0.0883 & 2308.151 & 2312.3 & 0.1798 & 1668.472 & 1670.3 & 0.1095 \\
\hline 8 & 2603.787 & 2605.8 & 0.0773 & 2308.153 & 2312.3 & 0.1797 & 1736.655 & 1738.3 & 0.0947 \\
\hline 9 & 2783.303 & 2789.1 & 0.2083 & 2603.5 & 2605.3 & 0.0691 & 2148.347 & 2155.9 & 0.3516 \\
\hline 10 & 2783.338 & 2789.1 & 0.207 & 2603.787 & 2605.3 & 0.0581 & 2165.632 & 2172.7 & 0.3264 \\
\hline
\end{tabular}


TABLE 5: Comparison of dimensionless frequency of non-stepped FG-CNTRC plate.

\begin{tabular}{|c|c|c|c|c|c|c|c|c|c|c|c|}
\hline \multirow{2}{*}{$\begin{array}{l}\text { Boundary } \\
\text { conditions }\end{array}$} & \multirow[b]{2}{*}{$b / h$} & \multirow[b]{2}{*}{$\Omega$} & \multicolumn{3}{|c|}{ FG-V } & \multicolumn{3}{|c|}{ FG-X } & \multicolumn{3}{|c|}{ FG-O } \\
\hline & & & $\begin{array}{c}\text { Reference } \\
{[16]}\end{array}$ & $\begin{array}{c}\text { Reference } \\
\text { [16] (ANSYS) }\end{array}$ & Present & $\begin{array}{c}\text { Reference } \\
{[16]}\end{array}$ & $\begin{array}{c}\text { Reference } \\
{[16] \text { (ANSYS) }}\end{array}$ & Present & $\begin{array}{c}\text { Reference } \\
{[16]}\end{array}$ & $\begin{array}{c}\text { Reference } \\
\text { [16] (ANSYS) }\end{array}$ & Present \\
\hline \multirow{10}{*}{ SSSS } & \multirow{5}{*}{10} & 1 & 12.452 & 12.495 & 12.486 & 14.616 & 14.659 & 14.655 & 11.55 & 11.6 & 11.581 \\
\hline & & 2 & 17.06 & 17.21 & 17.055 & 18.646 & 18.824 & 18.651 & 16.265 & 16.409 & 16.256 \\
\hline & & 3 & 19.499 & 19.479 & 19.569 & 19.499 & 19.479 & 19.554 & 19.499 & 19.479 & 19.595 \\
\hline & & 4 & 19.499 & 19.479 & 19.569 & 19.499 & 19.479 & 19.554 & 19.499 & 19.479 & 19.595 \\
\hline & & 5 & 27.34 & 27.524 & 27.009 & 28.519 & 28.742 & 28.2 & 26.513 & 26.687 & 26.179 \\
\hline & \multirow{5}{*}{20} & 1 & 15.11 & 15.103 & 15.136 & 19.939 & 19.916 & 19.975 & 13.523 & 13.531 & 13.542 \\
\hline & & 2 & 19.903 & 19.879 & 19.882 & 23.776 & 23.773 & 23.77 & 18.486 & 18.464 & 18.458 \\
\hline & & 3 & 31.561 & 31.233 & 31.12 & 34.389 & 34.123 & 33.977 & 30.166 & 29.83 & 29.719 \\
\hline & & 4 & 38.998 & 38.958 & 39.138 & 38.998 & 38.958 & 39.108 & 38.998 & 38.958 & 39.19 \\
\hline & & 5 & 38.998 & 38.958 & 39.138 & 38.998 & 38.958 & 39.108 & 38.998 & 38.958 & 39.19 \\
\hline \multirow{10}{*}{ CCCC } & \multirow{5}{*}{10} & 1 & 17.211 & 17.247 & 17.175 & 18.083 & 18.129 & 18.047 & 16.707 & 16.744 & 16.677 \\
\hline & & 2 & 22.818 & 22.922 & 22.65 & 23.606 & 23.728 & 23.438 & 22.253 & 22.353 & 22.089 \\
\hline & & 3 & 33.07 & 33.06 & 32.876 & 34.338 & 34.338 & 33.661 & 32.378 & 32.372 & 32.188 \\
\hline & & 4 & 33.552 & 33.534 & 32.903 & 34.467 & 34.464 & 34.303 & 32.857 & 32.837 & 32.228 \\
\hline & & 5 & 36.528 & 36.804 & 36.359 & 37.447 & 37.4 & 37.578 & 35.809 & 36.083 & 35.656 \\
\hline & \multirow{5}{*}{20} & 1 & 26.304 & 26.248 & 26.196 & 30.421 & 30.38 & 30.327 & 24.486 & 24.443 & 24.375 \\
\hline & & 2 & 31.496 & 31.405 & 31.262 & 35.036 & 35.003 & 34.839 & 29.795 & 29.699 & 29.55 \\
\hline & & 3 & 43.589 & 42.991 & 42.635 & 46.48 & 45.984 & 45.591 & 41.895 & 41.279 & 40.93 \\
\hline & & 4 & 56.249 & 55.894 & 55.76 & 61.98 & 61.692 & 61.558 & 53.557 & 53.204 & 53.058 \\
\hline & & 5 & 59.221 & 59.09 & 58.79 & 64.562 & 63.321 & 62.5 & 56.617 & 56.464 & 56.164 \\
\hline
\end{tabular}

TABLE 6: Comparison of natural frequency of multi-stepped FG-CNTRC plate.

\begin{tabular}{|c|c|c|c|c|c|c|c|c|c|}
\hline \multirow{3}{*}{ Frequency } & \multicolumn{9}{|c|}{ Boundary conditions } \\
\hline & \multicolumn{3}{|c|}{ CCCC } & \multicolumn{3}{|c|}{ SSSS } & \multicolumn{3}{|c|}{ CCFF } \\
\hline & Present & FEM & Error (\%) & Present & FEM & Error (\%) & Present & FEM & Error (\%) \\
\hline 1 & 369.1226 & 369.19 & 0.0182 & 264.3662 & 264.36 & 0.0023 & 304.0064 & 304.06 & 0.0176 \\
\hline 2 & 529.1282 & 529.65 & 0.0986 & 397.9645 & 398.28 & 0.0793 & 311.0388 & 311.12 & 0.0261 \\
\hline 3 & 718.3087 & 718.74 & 0.06 & 675.8775 & 676.34 & 0.0684 & 377.6699 & 377.61 & 0.0159 \\
\hline 4 & 794.5131 & 794.79 & 0.0349 & 678.0683 & 679.45 & 0.2038 & 383.4401 & 383.59 & 0.0391 \\
\hline 5 & 802.1168 & 803.97 & 0.231 & 714.4617 & 714.72 & 0.0362 & 571.7157 & 572.12 & 0.0707 \\
\hline 6 & 858.3181 & 858.66 & 0.0398 & 858.3178 & 858.53 & 0.0247 & 685.7125 & 686.27 & 0.0813 \\
\hline 7 & 976.337 & 977.74 & 0.1437 & 881.0082 & 881.9 & 0.1012 & 686.7083 & 687.17 & 0.0672 \\
\hline 8 & 1059.832 & 1061.1 & 0.1196 & 995.2035 & 998.67 & 0.3483 & 733.3032 & 733.49 & 0.0255 \\
\hline 9 & 1093.59 & 1095.8 & 0.2021 & 1021.29 & 1022.6 & 0.1282 & 827.5539 & 827.37 & 0.0222 \\
\hline 10 & 1118.368 & 1121.2 & 0.2532 & 1041.617 & 1042.6 & 0.0944 & 856.6614 & 857.66 & 0.1166 \\
\hline
\end{tabular}

Four kinds of transient loads employed in this research are represented in Figure 7, and the load functions are written as follows.

Rectangular pulse:

$$
f(t)= \begin{cases}f_{t}, & 0 \leq t \leq \tau, \\ 0, & t>\tau .\end{cases}
$$

Triangular pulse:

$$
f(t)= \begin{cases}\frac{2 t}{\tau} f_{t}, & 0 \leq t \leq \frac{\tau}{2}, \\ f_{t}-\frac{2}{\tau}\left(t-\frac{\tau}{2}\right) f_{t}, & \frac{\tau}{2} \leq t \leq \tau, \\ 0, & t>\tau .\end{cases}
$$

Half-sine pulse:

$$
f(t)= \begin{cases}f_{t} \sin \left(\frac{\pi t}{\tau}\right), & 0 \leq t \leq \tau, \\ 0, & t>\tau .\end{cases}
$$

Exponential pulse:

$$
f(t)= \begin{cases}f_{t} e^{-\xi t}, & 0 \leq t \leq \tau \\ 0, & t>\tau\end{cases}
$$

where $f_{t}$ is the load amplitude; $\tau$ is the pulse width; and $t$ is the time variable.

Figure 8 presents the comparison results of transient response data between the proposed method and finite element software ABAQUS. The geometric parameters, material constants, and boundary conditions are set as shown in 


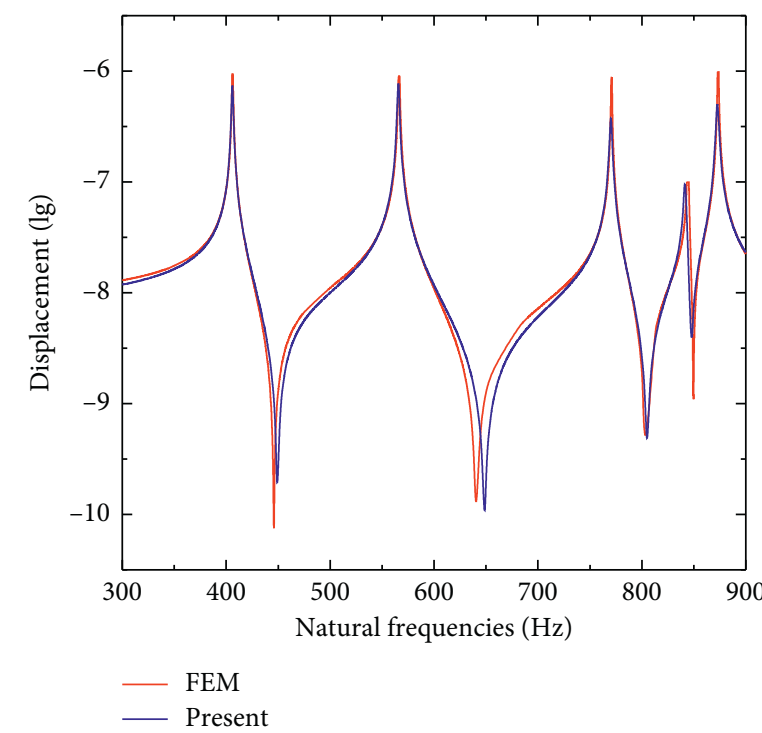

(a)

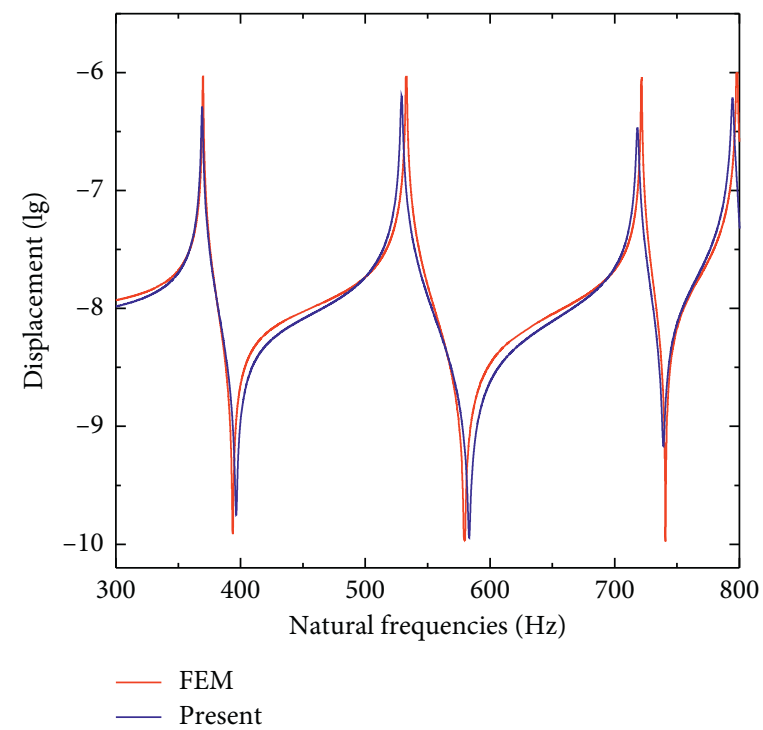

(b)

FIGURE 6: The comparison of vertical displacement of FG-CNTRC plate. (a) Non-stepped FG-CNTRC plate. (b) Multi-stepped FG-CNTRC plate.

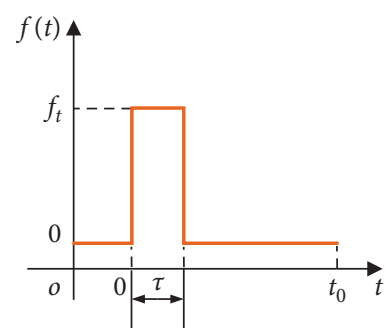

(a)

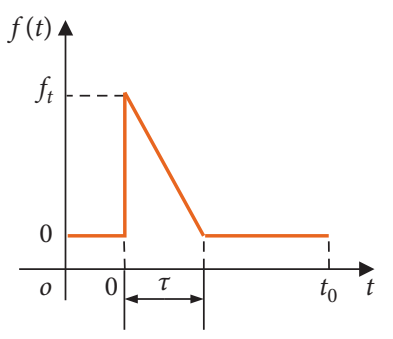

(b)

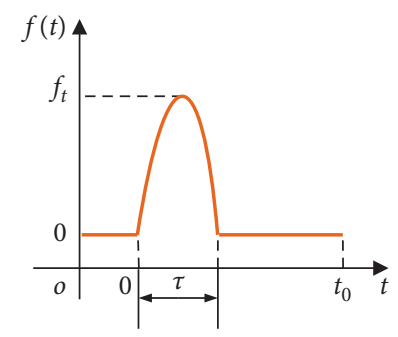

(c)

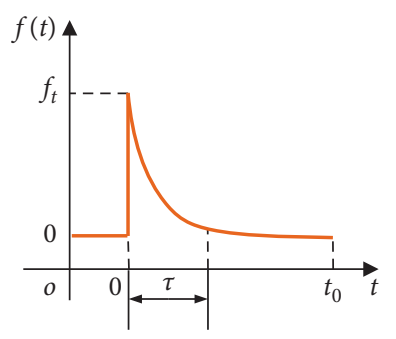

(d)

FIgURE 7: Load pulse shapes. (a) Rectangular pulse; (b) triangular pulse; (c) half-sine pulse; (d) exponential pulse.

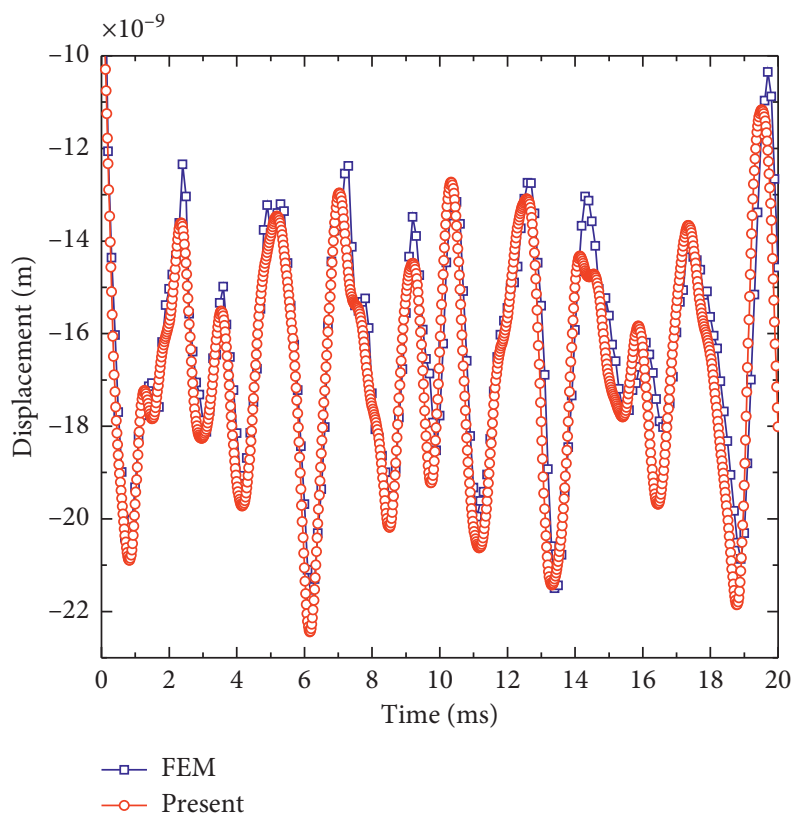

(a)

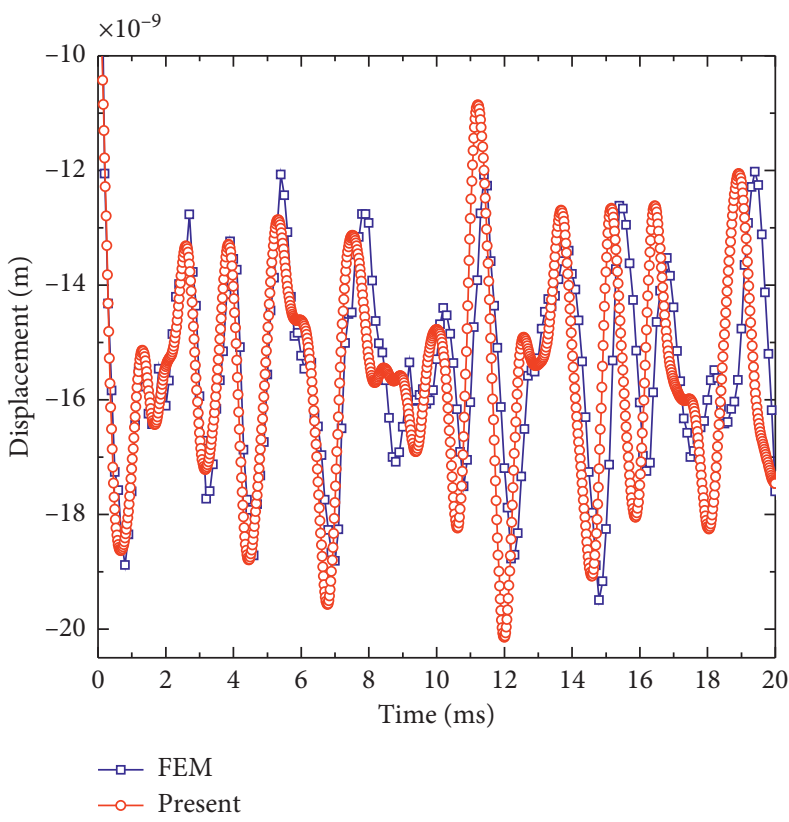

(b)

FIGURE 8: The comparison of normal displacement response of FG-CNTRC plate. (a) Non-stepped FG-CNTRC plate. (b) Multi-stepped FGCNTRC plate. 
Figure 6. Here, the transient load $f(t)$ is set as rectangular pulse and the amplitude of the rectangular pulse is set as $f_{t}=-1 \mathrm{~N}$. The calculating time step is $\Delta t=0.02 \mathrm{~ms}$, and the loading time $\tau$ and calculating time are set as $20 \mathrm{~ms}$, respectively. The results indicate that the prediction accuracy of the suggested method agrees well with that of the finite element method; therefore, the accuracy of the proposed method is validated.

\section{Numerical Example}

Based on the convergence and validity study of the proposed method, in this section, the results of free and forced vibration analysis of the FG-CNTRC plate are suggested. The material properties for the CNTRC plate studied here and the CNT efficient parameters are as follows [56]:

$$
\begin{aligned}
E^{m} & =2.5 \mathrm{GPa}, \\
\rho^{m} & =1150 \mathrm{~kg} / \mathrm{m}^{3}, \\
\mu^{m} & =0.34, \\
\rho^{\mathrm{CNT}} & =1400 \mathrm{~kg} / \mathrm{m}^{3}, \\
\mu^{\mathrm{CNT}} & =0.175, \\
E_{11}^{\mathrm{CNT}} & =5.6446 \mathrm{TPa}, \\
E_{22}^{\mathrm{CNT}} & =7.08 \mathrm{TPa}, \\
G_{12}^{\mathrm{CNT}} & =1.9445 \mathrm{TPa}, \\
V_{\mathrm{CNT}}^{*} & =0.12, \\
\eta_{1} & =0.137, \\
\eta_{2} & =1.022, \\
\eta_{3} & =0.715, \\
V_{\mathrm{CNT}}^{*} & =0.17, \\
\eta_{1} & =0.142, \\
\eta_{2} & =1.626, \\
\eta_{3} & =1.138, \\
V_{\mathrm{CNT}}^{*} & =0.28, \\
\eta_{1} & =0.141, \\
\eta_{2} & =1.585, \\
\eta_{3} & =1.109 .
\end{aligned}
$$

4.1. Free Vibration. Here, according to the several classic and elastic boundary conditions and material parameters, new natural frequency results and mode types of FG-CNTRC plate are suggested. The geometric parameters of FCCNTRC plate are $a=1 \mathrm{~m}, b=1 \mathrm{~m}$, and $h=0.1 \mathrm{~m}$. Table 7 shows the results of dimensionless frequency in the nonstepped FG-CNTRC plate according to different material distribution characteristics under the four-side fully clamped boundary condition. As can be seen from Table 7, as $V_{\mathrm{CNT}}^{*}$ increases, the dimensionless frequency of the FGCNTRC plate is also increased. Also, when the material distributions are FG- $\Lambda$ and FG-V, the non-dimensional frequencies are same; therefore, FG- $\Lambda$ is not considered in the following process. In the non-stepped FG-CNTRC, under the same $V_{\mathrm{CNT}}^{*}$ condition, the dimensionless frequency is the highest when the material distribution is FG-X, while it is the lowest in case of FG-O.

Table 8 shows the results of dimensionless frequency in the multi-stepped FG-CNTRC plate according to different material distributions under the several classic classical and elastic boundary conditions. The material properties are considered when $V_{\mathrm{CNT}}^{*}=0.17, \eta_{1}=0.142, \eta_{2}=1.626$, and $\eta_{3}=1.138$ and the geometric parameters are as follows: $a_{1}=0.5 \mathrm{~m}, a_{2}=0.1 \mathrm{~m}, a_{3}=0.5 \mathrm{~m}, b_{1}=0.5 \mathrm{~m}, b_{2}=0.1 \mathrm{~m}$, $b_{3}=0.5 \mathrm{~m}, \quad h_{x 1}=0.02 \mathrm{~m}, \quad h_{x 2}=0.05 \mathrm{~m}, \quad h_{x 3}=0.02 \mathrm{~m}$, $h_{y 1}=0.02 \mathrm{~m}, h_{y 2}=0.05 \mathrm{~m}$, and $h_{y 3}=0.05 \mathrm{~m}$. Table 8 shows that the dimensionless frequencies of multi-stepped FGCNTRC plate are different according to the boundary conditions.

In the multi-stepped FG-CNTRC plate, similar to Table 7 , the dimensionless frequency is the highest in case of FG-X, while it is the lowest in case of FG-O. Figure 9 shows the mode types of the multi-stepped FG-CNTRC plate corresponding to the FG-X under the boundary conditions including CCCC and CCFF of Table 8.

To help readers understand the mode shapes of the multi-stepped FG-CNTRC plate, Figures 10-12 show visually the different shapes of modes in the multi-stepped FGCNTRC plate with different kinds of boundary conditions, material properties, material distribution, and number of steps.

\subsection{Forced Vibration}

4.2.1. Steady-State Vibration Analysis. This section is mainly focused on the frequency-displacement characteristics of the multi-stepped FG-CNTRC plate. Figure 13 shows the frequency-displacement characteristics of the multi-stepped FG-CNTRC plate with different material distributions under the four-side fully clamped boundary conditions when three types of loads are applied.

The material and geometric properties are the same as Table 6 , and $V_{\mathrm{CNT}}^{*}=0.12, \eta_{1}=0.137, \eta_{2}=1.022$, and $\eta_{3}=0.715$, respectively. The applied points of force are at $A$ $(x, y)=(0.3 \mathrm{~m}, 0.3 \mathrm{~m}), A\left(x_{1}, y_{1}-x_{2}, y_{2}\right)=(0.3 \mathrm{~m}, 0.3 \mathrm{~m}-0.4 \mathrm{~m}$, $0.3 \mathrm{~m})$, and $A\left(x_{1}, y_{1}-x_{2}, y_{2}\right)=(0.3 \mathrm{~m}, 0.3 \mathrm{~m}-0.4 \mathrm{~m}, 0.4 \mathrm{~m})$ in cases of point force, line force, and area force, respectively. The external force is assumed that the uniform load $\left(f_{w}=-1 \mathrm{~N}\right)$ is applied in the rectangular direction. It can be clearly seen that the external load cannot alter the natural frequency of the multi-stepped FG-CNTRC plate itself. However, regardless of the material distribution, at the same frequency, the displacement is the largest in the application of point force, while it is the smallest in case of area force. When the line force is applied, the displacement is medium. Figure 14 shows the frequency-displacement characteristics of the multi-stepped FG-CNTRC plate according to the different $V_{\mathrm{CNT}}^{*}$ when the point force is applied under the several boundary conditions. The material and geometric 
TABLE 7: The dimensionless frequencies of non-stepped FG-CNTRC plate.

\begin{tabular}{|c|c|c|c|c|c|c|c|c|c|c|c|}
\hline \multirow{2}{*}{$V_{\mathrm{CNT}}^{*}$} & & \multicolumn{10}{|c|}{ Modes } \\
\hline & & 1 & 2 & 3 & 4 & 5 & 6 & 7 & 8 & 9 & 10 \\
\hline \multirow{5}{*}{0.12} & UD & 3.9703 & 5.3905 & 7.4569 & 7.9074 & 8.3479 & 9.3876 & 10.197 & 11.081 & 11.404 & 11.927 \\
\hline & FG- $\Lambda$ & 3.8912 & 5.3554 & 7.3247 & 7.9114 & 8.2569 & 9.4264 & 10.155 & 11.114 & 11.277 & 11.923 \\
\hline & FG-V & 3.8912 & 5.3554 & 7.3247 & 7.9114 & 8.2569 & 9.4264 & 10.155 & 11.114 & 11.277 & 11.923 \\
\hline & FG-X & 4.0694 & 5.5216 & 7.6146 & 8.0819 & 8.5201 & 9.4799 & 10.398 & 11.297 & 11.561 & 12.009 \\
\hline & FG-O & 3.7855 & 5.2288 & 7.1826 & 7.7538 & 8.1035 & 9.4417 & 9.9794 & 10.927 & 11.127 & 11.766 \\
\hline \multirow{5}{*}{0.17} & UD & 5.0879 & 6.9378 & 9.5634 & 10.201 & 10.729 & 12.129 & 13.135 & 14.308 & 14.663 & 15.407 \\
\hline & FG- $\Lambda$ & 4.9857 & 6.908 & 9.4035 & 10.241 & 10.634 & 12.229 & 13.119 & 14.404 & 14.52 & 15.375 \\
\hline & FG-V & 4.9857 & 6.908 & 9.4035 & 10.241 & 10.634 & 12.229 & 13.119 & 14.404 & 14.52 & 15.375 \\
\hline & FG-X & 5.2593 & 7.1885 & 9.8249 & 10.554 & 11.037 & 12.352 & 13.521 & 14.757 & 14.947 & 15.616 \\
\hline & FG-O & 4.8246 & 6.6885 & 9.2026 & 9.9475 & 10.393 & 12.264 & 12.816 & 14.046 & 14.308 & 15.135 \\
\hline \multirow{5}{*}{0.28} & UD & 5.4321 & 7.3333 & 10.197 & 10.724 & 11.379 & 12.708 & 13.857 & 15.012 & 15.538 & 16.155 \\
\hline & $\mathrm{FG}-\Lambda$ & 5.4472 & 7.4397 & 10.245 & 10.95 & 11.502 & 13.053 & 14.091 & 15.365 & 15.733 & 16.575 \\
\hline & FG-V & 5.4472 & 7.4397 & 10.245 & 10.95 & 11.502 & 13.053 & 14.091 & 15.365 & 15.733 & 16.575 \\
\hline & FG-X & 5.7266 & 7.8639 & 10.654 & 11.544 & 11.995 & 13.168 & 14.717 & 16.105 & 16.109 & 16.676 \\
\hline & FG-O & 5.2877 & 7.1001 & 10.086 & 10.41 & 11.214 & 13.173 & 13.619 & 14.666 & 15.616 & 16.385 \\
\hline
\end{tabular}

TAвLE 8: The dimensionless frequencies of multi-stepped FG-CNTRC plate with different boundary conditions.

\begin{tabular}{|c|c|c|c|c|c|c|c|c|c|}
\hline & \multirow{2}{*}{ Modes } & \multicolumn{8}{|c|}{ Boundary conditions } \\
\hline & & $\mathrm{CCCC}$ & SSSS & $\mathrm{CCFF}$ & CCSS & CFCF & $\mathrm{E}^{1} \mathrm{E}^{1} \mathrm{CC}$ & $\mathrm{E}^{2} \mathrm{E}^{2} \mathrm{CC}$ & $\mathrm{E}^{3} \mathrm{E}^{3} \mathrm{CC}$ \\
\hline \multirow{4}{*}{ UD } & 1 & 11.878 & 6.3101 & 8.4369 & 10.407 & 1.763 & 10.416 & 11.735 & 10.354 \\
\hline & 2 & 12.355 & 7.2558 & 8.6606 & 10.773 & 3.2095 & 11.923 & 12.326 & 11.922 \\
\hline & 3 & 19.465 & 13.214 & 11.804 & 16.69 & 6.6438 & 18.17 & 19.348 & 18.124 \\
\hline & 4 & 24.726 & 17.842 & 12.575 & 22.531 & 9.3149 & 21.39 & 24.666 & 21.382 \\
\hline \multirow{4}{*}{ FG-V } & 1 & 10.71 & 5.3941 & 7.1506 & 9.5077 & 1.7169 & 9.6103 & 10.604 & 9.5606 \\
\hline & 2 & 11.626 & 6.85 & 7.4179 & 9.6381 & 3.2676 & 11.334 & 11.604 & 11.345 \\
\hline & 3 & 18.872 & 12.917 & 10.622 & 15.928 & 6.8569 & 17.884 & 18.8 & 17.857 \\
\hline & 4 & 22.016 & 15.53 & 11.855 & 21.392 & 7.8366 & 19.832 & 21.972 & 19.823 \\
\hline \multirow{4}{*}{ FG-X } & 1 & 13.299 & 7.3699 & 9.8674 & 11.795 & 2.2367 & 11.306 & 13.125 & 11.23 \\
\hline & 2 & 13.705 & 8.0438 & 10.084 & 12.194 & 4.0422 & 13.013 & 13.666 & 13.007 \\
\hline & 3 & 20.96 & 14.344 & 13.195 & 18.154 & 7.4092 & 19.289 & 20.819 & 19.255 \\
\hline & 4 & 27.991 & 20.757 & 13.879 & 22.693 & 10.872 & 22.956 & 27.912 & 22.953 \\
\hline \multirow{4}{*}{ FG-O } & 1 & 9.7402 & 4.8733 & 6.3391 & 8.6141 & 1.44 & 8.8857 & 9.6834 & 8.8171 \\
\hline & 2 & 10.775 & 6.4673 & 6.6011 & 8.6944 & 2.9381 & 10.565 & 10.795 & 10.55 \\
\hline & 3 & 17.738 & 12.084 & 9.6518 & 14.858 & 6.3165 & 16.969 & 17.662 & 16.937 \\
\hline & 4 & 19.906 & 13.98 & 10.979 & 19.273 & 6.9302 & 18.448 & 19.902 & 18.418 \\
\hline
\end{tabular}
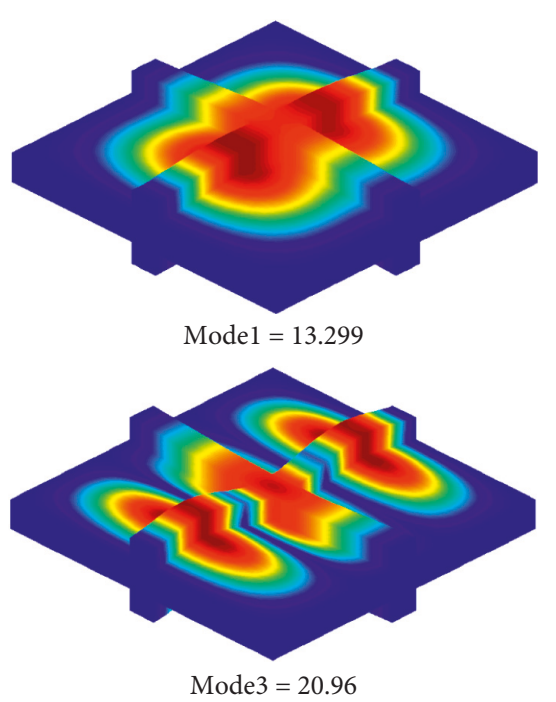

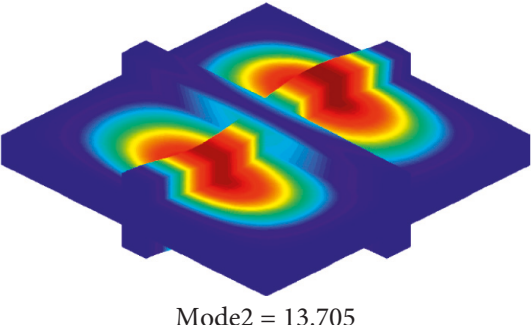

Mode2 $=13.705$

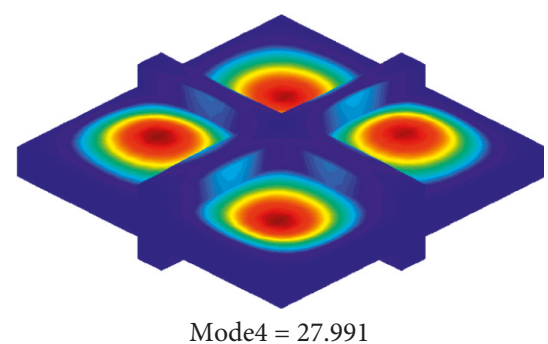

Mode4 = 27.991

(a)

Figure 9: Continued. 

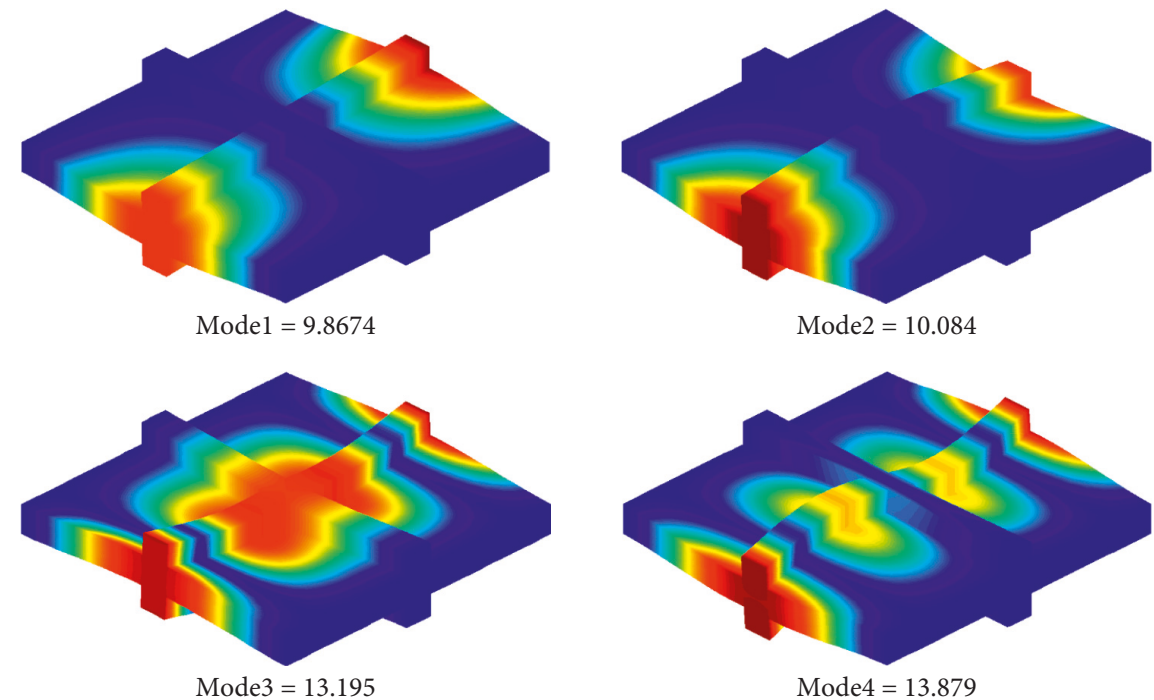

(b)

Figure 9: Some mode shapes of multi-stepped FG-CNTRC plate. (a) CCCC. (b) CCFF.

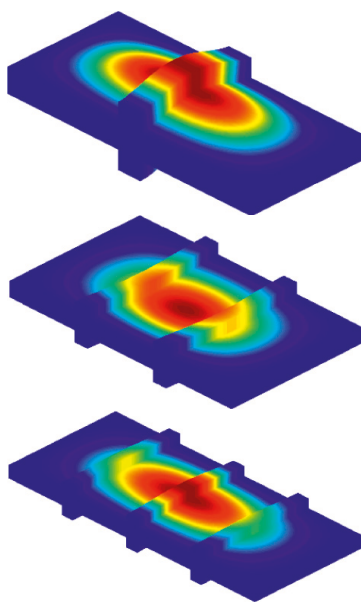

(a)

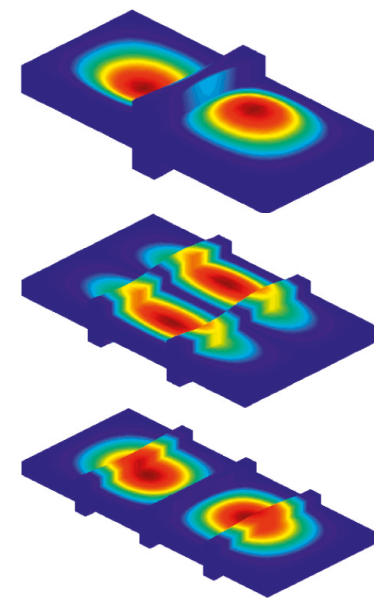

(b)

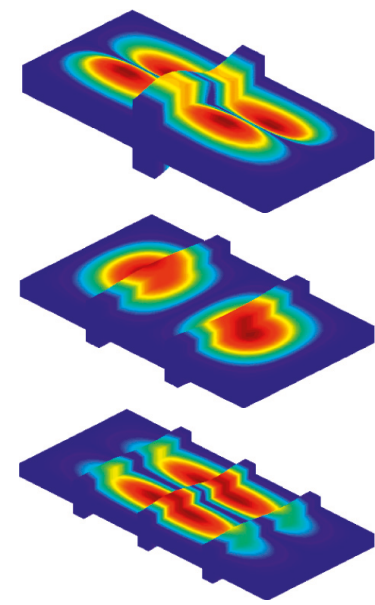

(c)

FIGURE 10: Some mode shapes of multi-stepped FG-CNTRC plate with CCCC boundary condition $\left(\mathrm{FG}-\mathrm{V}, V_{\mathrm{CNT}}^{*}=0.28, \eta_{1}=0.141\right.$, $\eta_{2}=1.585, \eta_{3}=1.109$ ). (a) Mode1. (b) Mode2. (c) Mode3.

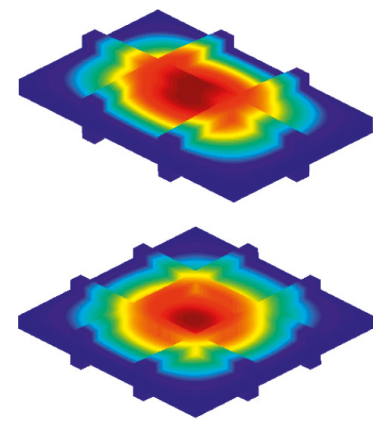

(a)

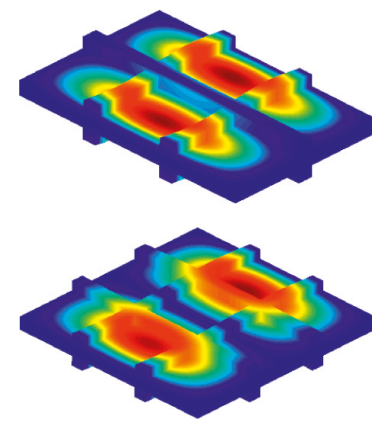

(b)

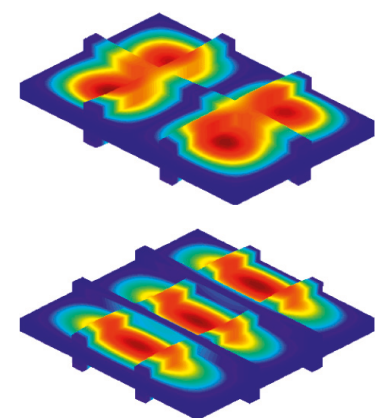

(c)

FIGURE 11: Some mode shapes of multi-stepped FG-CNTRC plate with SSSS boundary condition (FG-O, $V_{\mathrm{CNT}}^{*}=0.12, \eta_{1}=0.137, \eta_{2}=1.022$, $\eta_{3}=0.715$ ). (a) Mode1. (b) Mode2. (c) Mode3. 


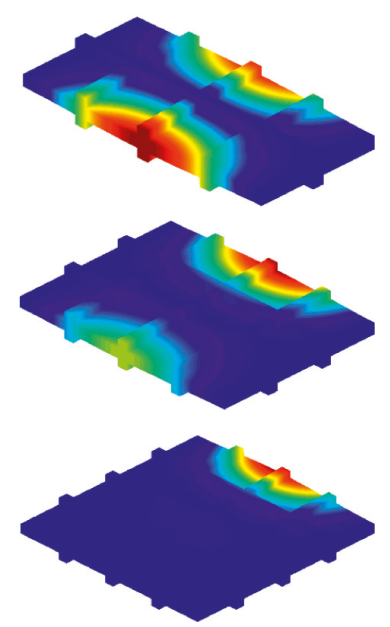

(a)
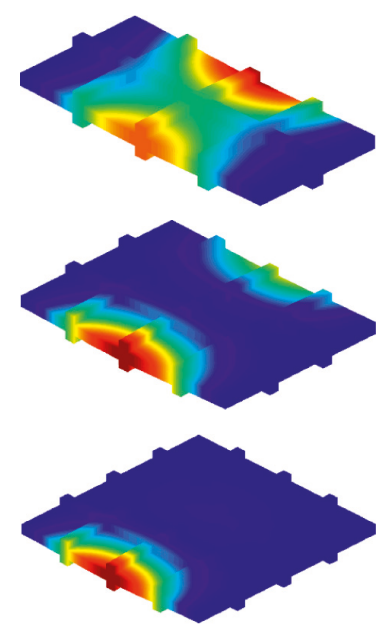

(b)

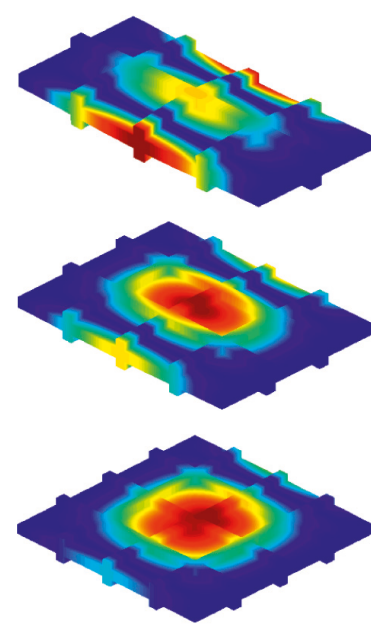

(c)

FIGURE 12: Some mode shapes of multi-stepped FG-CNTRC plate with CCFF boundary condition $\left(\mathrm{FG}-\mathrm{X}, V_{\mathrm{CNT}}^{*}=0.17, \eta_{1}=0.142\right.$, $\eta_{2}=1.626, \eta_{3}=1.138$ ). (a) Mode1. (b) Mode2. (c) Mode3.

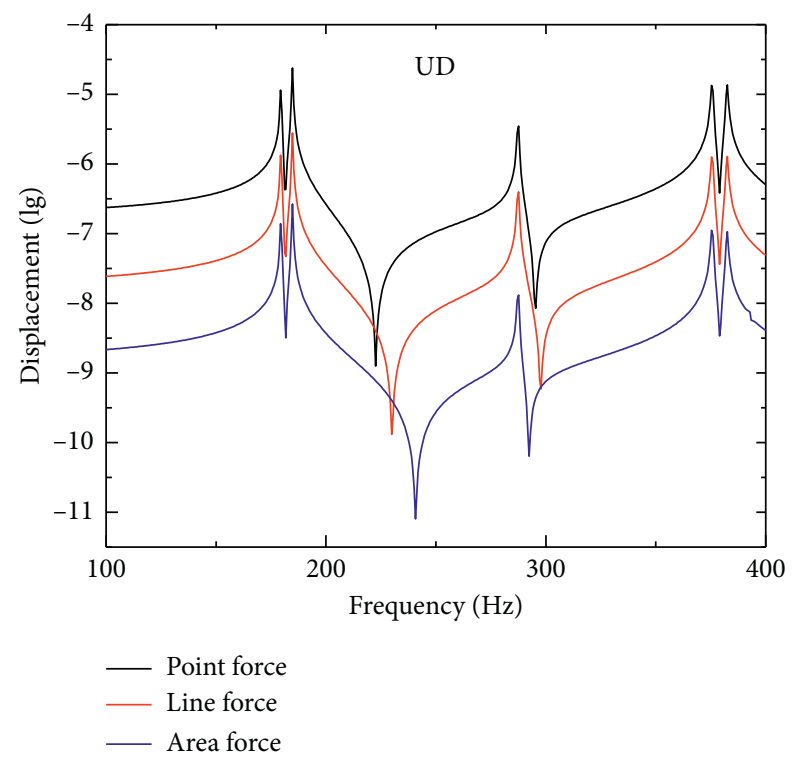

(a)

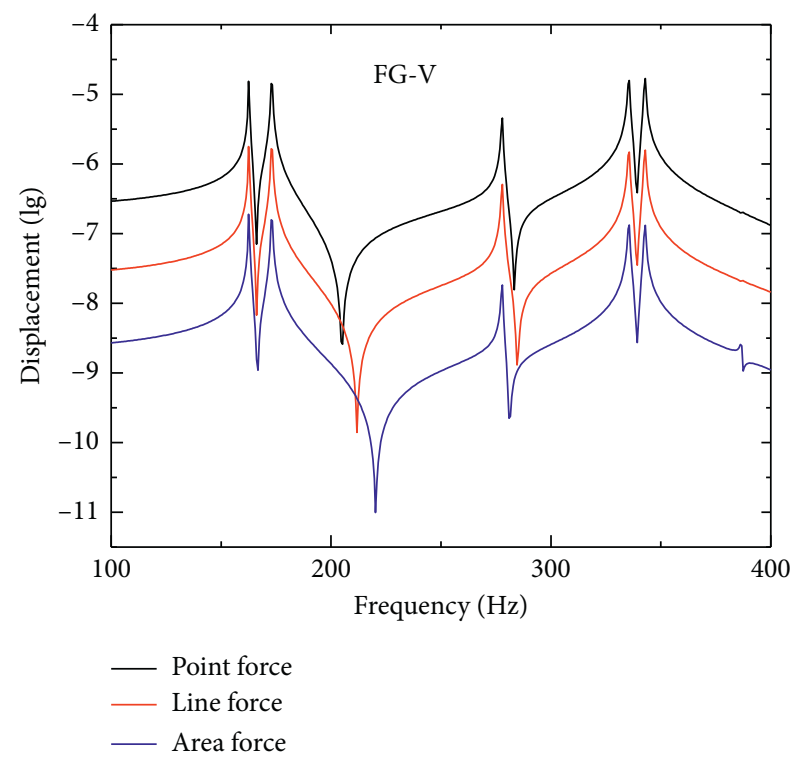

(b)

Figure 13: Continued. 


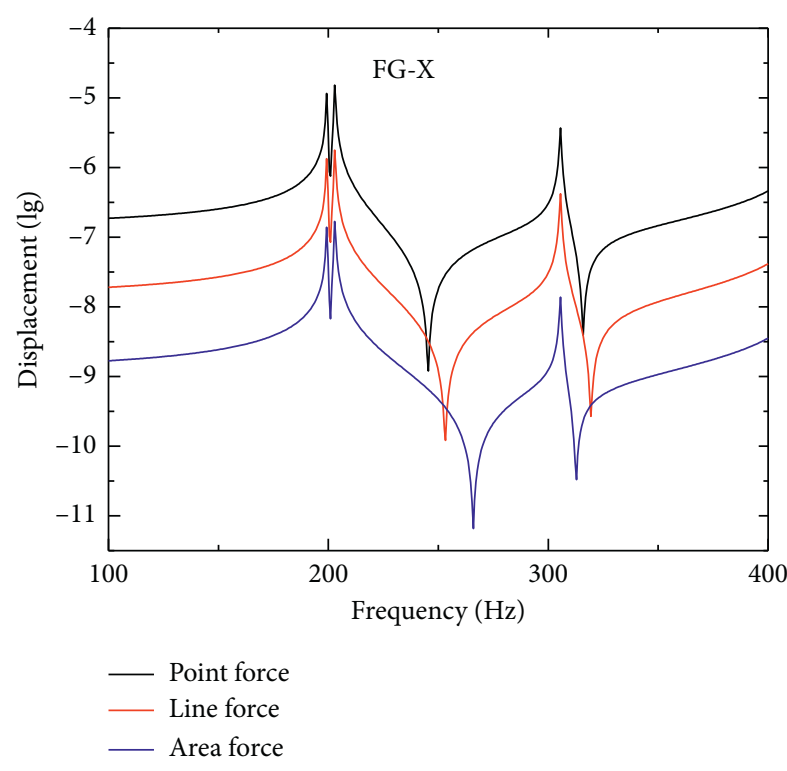

(c)

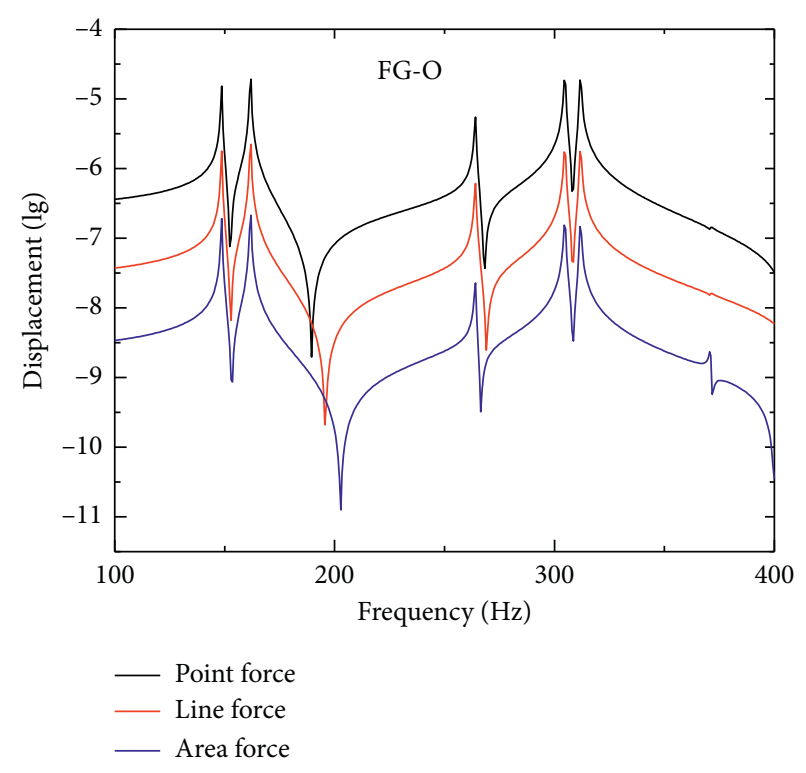

(d)

FIGURE 13: The frequency-displacement characteristics of multi-stepped FG-CNTRC plate under three types of load.
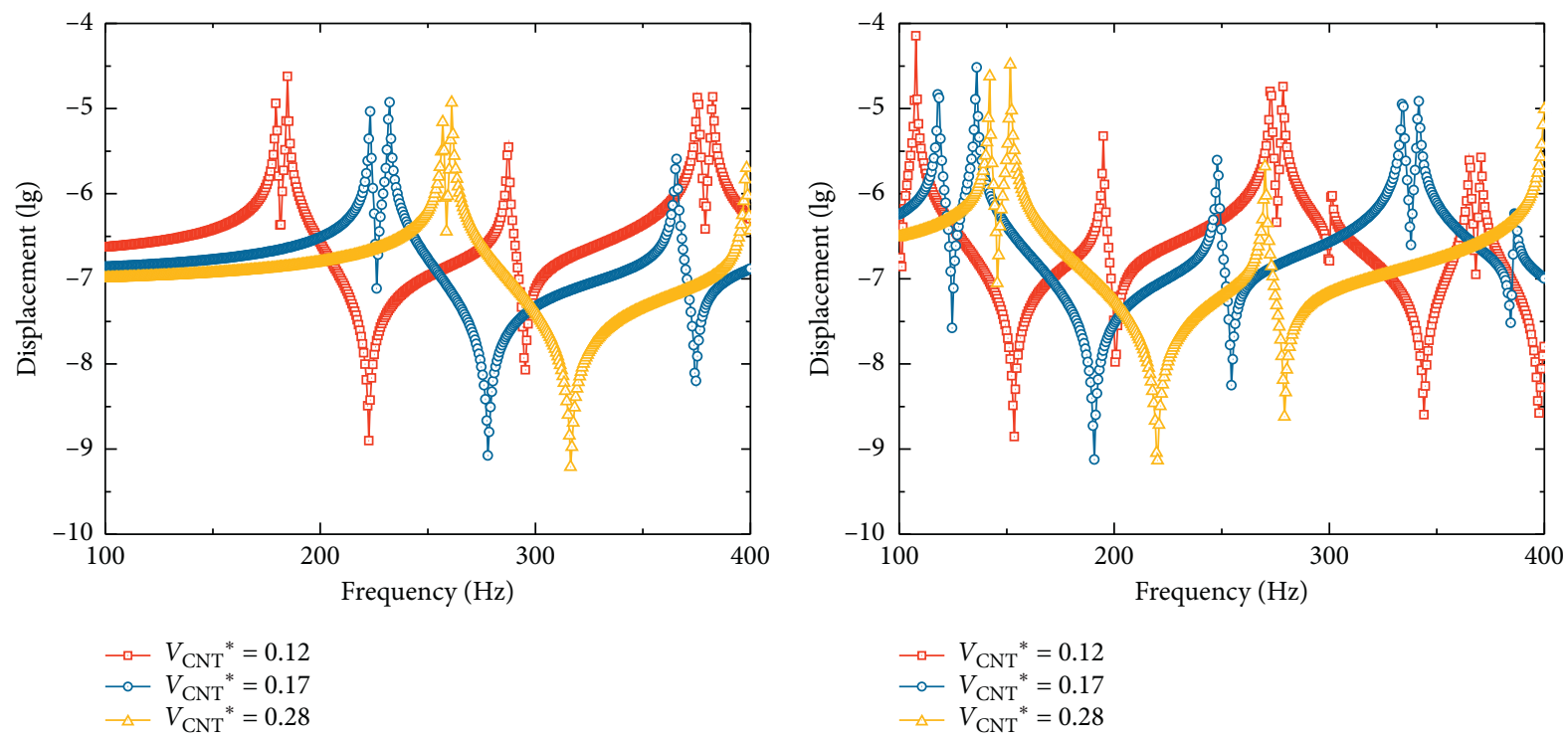

(a)

(b)

Figure 14: Continued. 


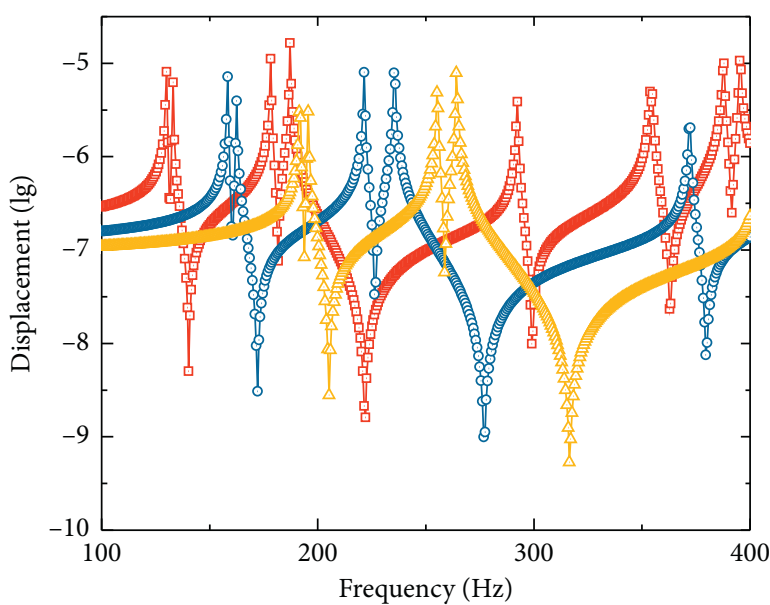

$\multimap-V_{\mathrm{CNT}^{*}}{ }^{*}=0.12$
$\multimap-V_{\mathrm{CNT}}{ }^{*}=0.17$
$\square-V_{\mathrm{CNT}}{ }^{*}=0.28$

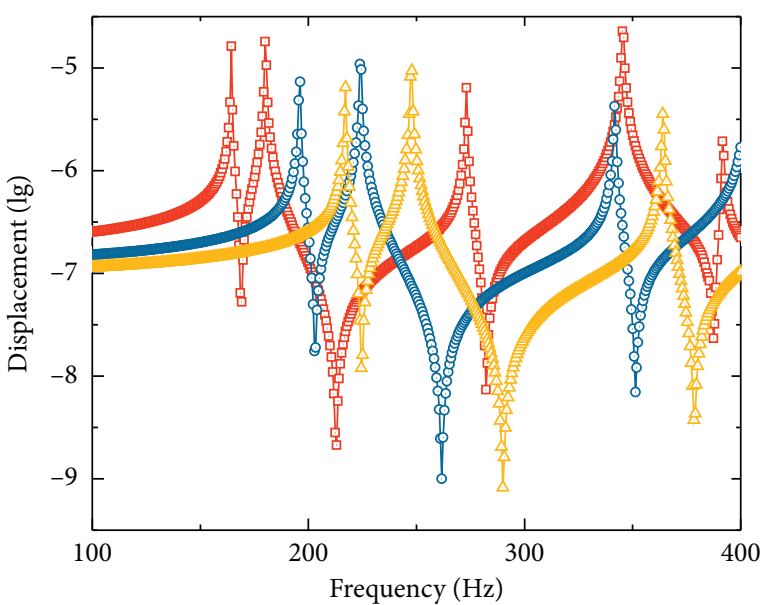

$\multimap-V_{\mathrm{CNT}^{*}}{ }^{*}=0.12$
$\multimap-V_{\mathrm{CNT}}{ }^{*}=0.17$
$\square-V_{\mathrm{CNT}}{ }^{*}=0.28$

(c)

(d)

FIGURE 14: The frequency-displacement characteristics of multi-stepped FG-CNTRC plate under three types of $V_{\mathrm{CNT}}^{*}$. (a) CCCC. (b) SSSS. (c) CCFF. (d) $\mathrm{E}_{1} \mathrm{E}_{1} \mathrm{CC}$.

properties are set the same as Figure 13. The examples of free vibration analysis clearly show that as $V_{\mathrm{CNT}}^{*}$ increases, the frequency of multi-stepped FG-CNTRC plate also increases.

As the last example of the steady-state vibration analysis, the frequency-displacement characteristics in the nonstepped and stepped plants with same size are considered. Materials have FG-X distribution and the study is conducted when $V_{\mathrm{CNT}}^{*}=0.12, \eta_{1}=0.137, \eta_{2}=1.022$, and $\eta_{3}=0.715$. The geometric parameters are $a=1.1 \mathrm{~m}, b=1.1 \mathrm{~m}$, and $h=0.02 \mathrm{~m}$ in the non-stepped plates and $a_{1}=0.5 \mathrm{~m}, a_{2}=0.1 \mathrm{~m}$, $a_{3}=0.5 \mathrm{~m}, b_{1}=0.5 \mathrm{~m}, b_{2}=0.1 \mathrm{~m}, b_{3}=0.5 \mathrm{~m}, h_{x 1}=0.02 \mathrm{~m}$, $h_{x 2}=0.05 \mathrm{~m}, h_{x 3}=0.02 \mathrm{~m}, h_{y 1}=0.02 \mathrm{~m}, h_{y 2}=0.05 \mathrm{~m}$, and $h_{y 3}=0.02 \mathrm{~m}$ in stepped plates, respectively.

The external load is assumed that the unit point force $\left(f_{w}=-1 \mathrm{~N}\right)$ is applied in the vertical direction. The applied points of force are all set as $A(x, y)=(0.55 \mathrm{~m}$, $0.55 \mathrm{~m})$ in two cases, and the displacement measurement points are all taken as $B(x, y)=(0.3 \mathrm{~m}, 0.3 \mathrm{~m})$ in all cases. Figure 15 shows the frequency-displacement characteristics curve in two cases under different boundary conditions.

Figure 15 shows that the frequency is expressed largely in the stepped plates while the displacement is seen largely in the non-stepped plates, which is mainly due to the resisting force of the steps.

4.2.2. Transient Response. Figure 16 shows the displacement of multi-stepped FG-CNTRC plate under CCCC boundary condition when three types of load are applied. The material and geometric parameters are set as shown in Table 6, and the size and applied point of force and response measurement point of displacement are the same as Figure 13. The transient load $f(t)$ is set as rectangular pulse, and the calculating time step, loading time, and calculating time are taken as $\Delta t=0.02 \mathrm{~ms}, \tau=10 \mathrm{~ms}$, and $t=20 \mathrm{~ms}$. As can be seen from Figure 16, in the application of point force, the displacement change according to the time is the largest, while the displacement change is the smallest in case of area force.

Figure 17 shows the displacement of multi-stepped FGCNTRC plate when various transient loads are applied. The material has FG-V distribution characteristics; the study is conducted when $V_{\mathrm{CNT}}^{*}=0.12, \eta_{1}=0.137, \eta_{2}=1.022$, and $\eta_{3}=0.715$. The type of applied force is point force, and the size, applied point of force, and displacement-response measurement point are set as shown in Figure 16. The calculating time step is taken as $\Delta t=0.02 \mathrm{~ms}$, and the loading time and calculation time are $\tau=10 \mathrm{~ms}$ and $t=20 \mathrm{~ms}$, respectively. As can be seen from Figure 17, the transient response exhibited by the exponential pulse is the largest, while it is the smallest in case of the rectangular pulse. In addition, the change of displacement is very slow when the half-sine pulse and triangular pulse are applied. Overall results indicate that the variation of transient response of the multi-stepped FG-CNTRC plate has a close relationship with the type of applied loads.

Figure 18 represents the influence of $V_{\mathrm{CNT}}^{*}$ on the transient response of multi-stepped FG-CNTRC plate when different kinds of transient loads are applied. The material is assumed to have FG-V distribution characteristics, and the clamped boundary condition is considered. The material and geometric parameters and the parameters of displacementresponse characteristics including the applied force and applied time are set as shown in Figure 17. Figure 18 shows that as $V_{\mathrm{CNT}}^{*}$ increases, the displacement also increases. Also, if the only absolute variation of displacement is considered, it is the largest when $V_{\mathrm{CNT}}^{*}=0.12$ regardless of the type of transient loads. 


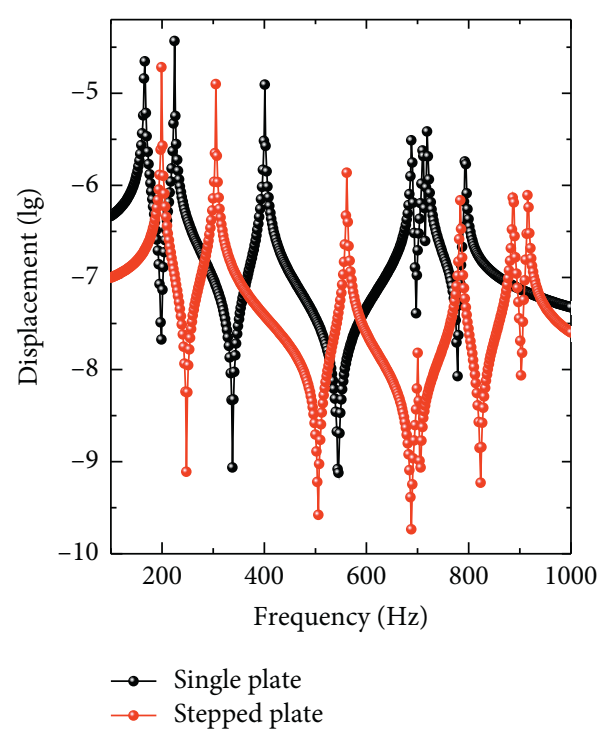

(a)

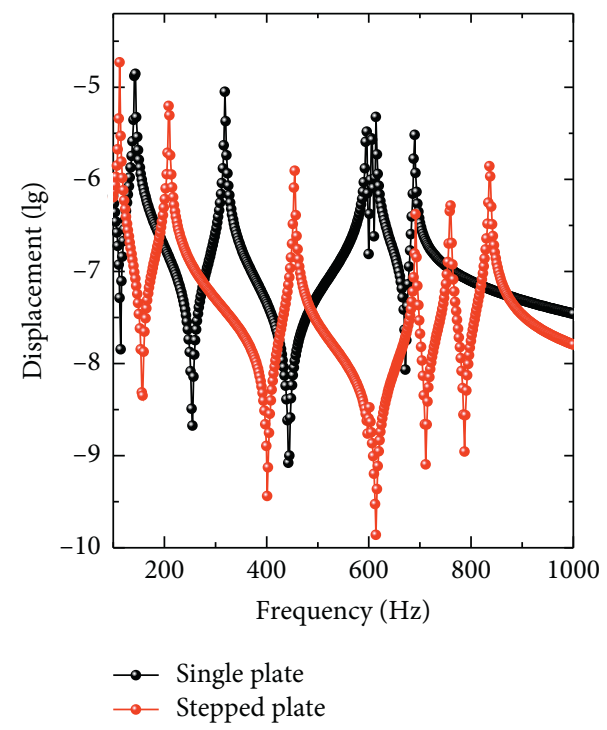

(b)

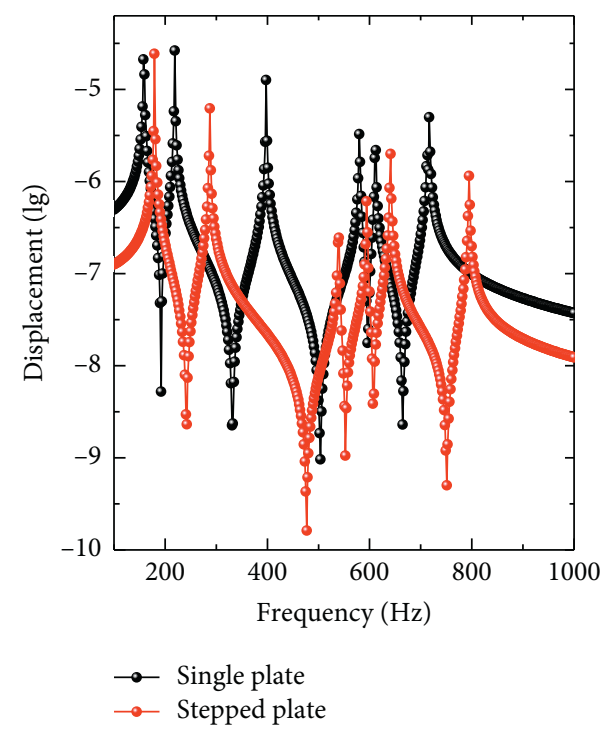

(c)

FIGURE 15: The frequency-displacement characteristics of non-stepped and multi-stepped FG-CNTRC plates. (a) CCCC. (b) SSSS. (c) $\mathrm{E}_{1} \mathrm{E}_{1} \mathrm{CC}$.

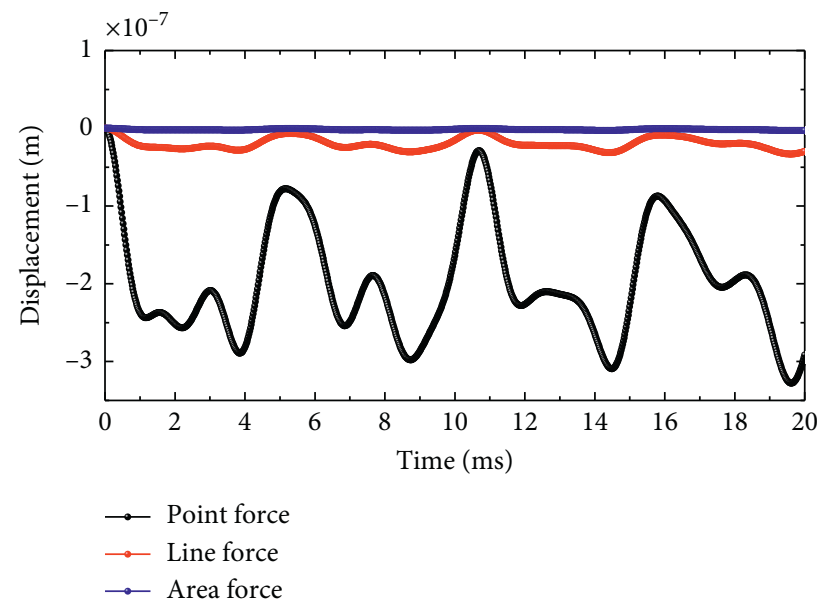

FIGURE 16: The displacement response of multi-stepped FG-CNTRC plate under different load types. 

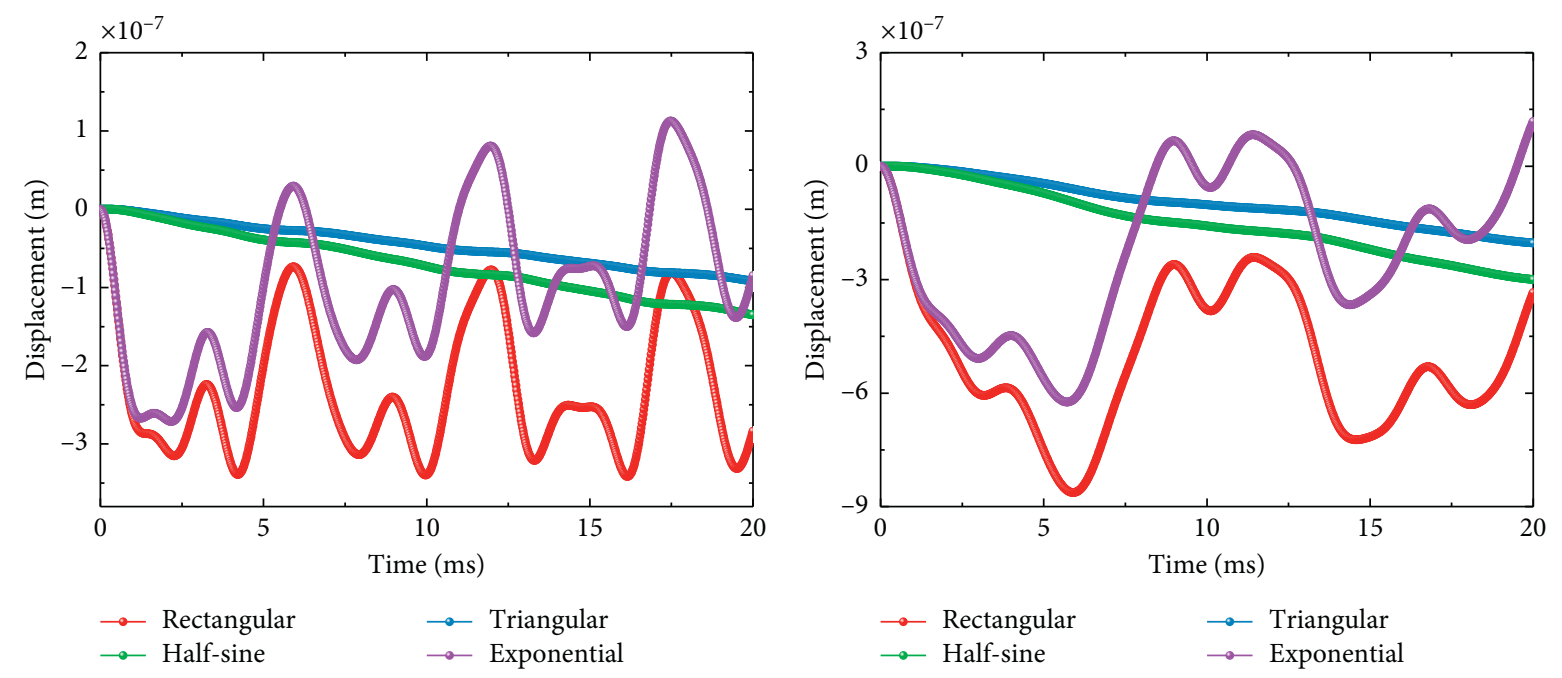

(a)

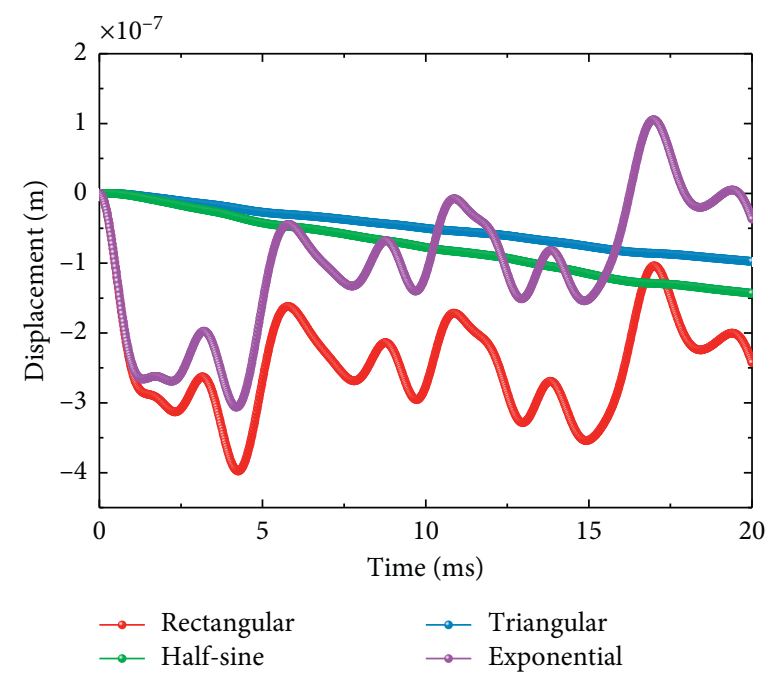

(c)

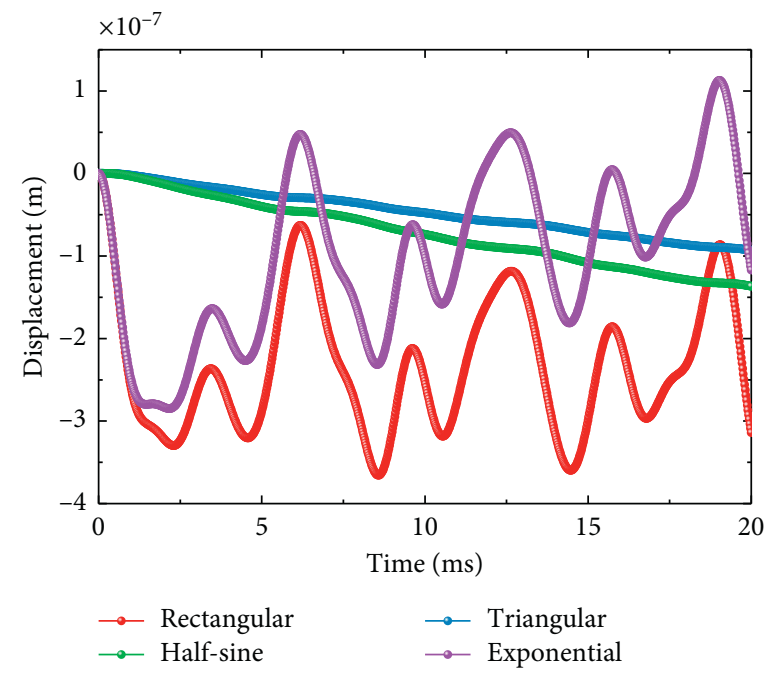

(d)

FIGURE 17: The displacement response of multi-stepped FG-CNTRC with various boundary conditions. (a) CCCC. (b) SSSS. (c) CCFF. (d) $\mathrm{E}_{1} \mathrm{E}_{1} \mathrm{CC}$. 


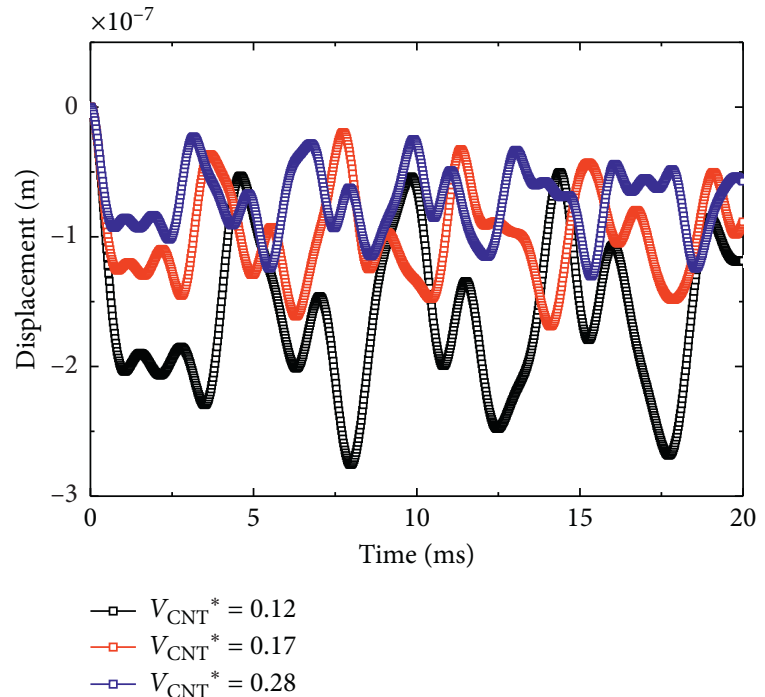

(a)

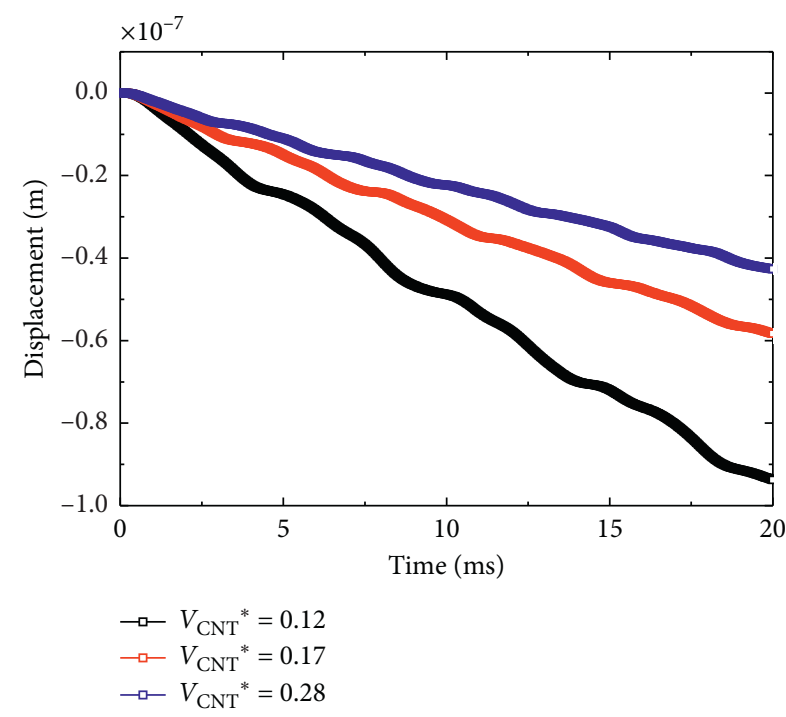

(c)

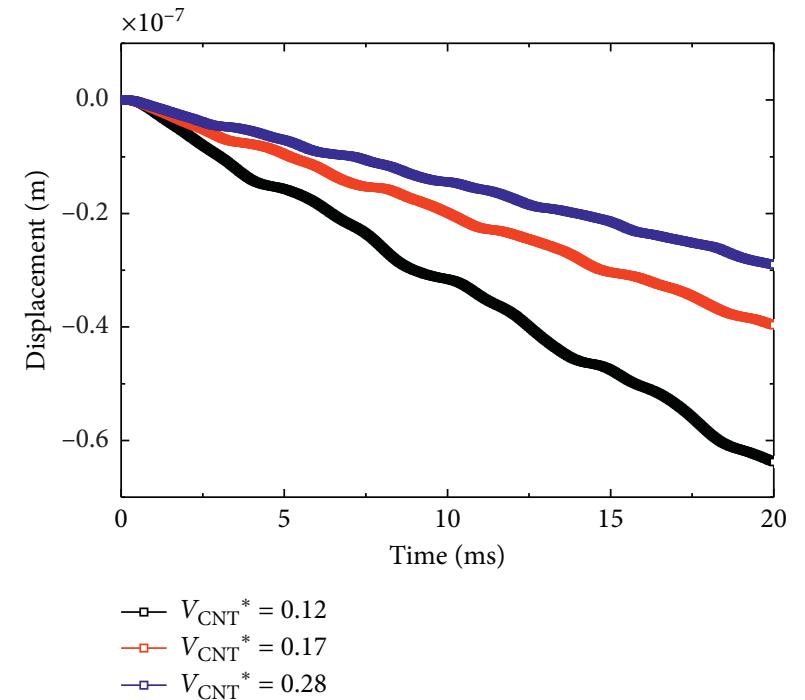

(b)

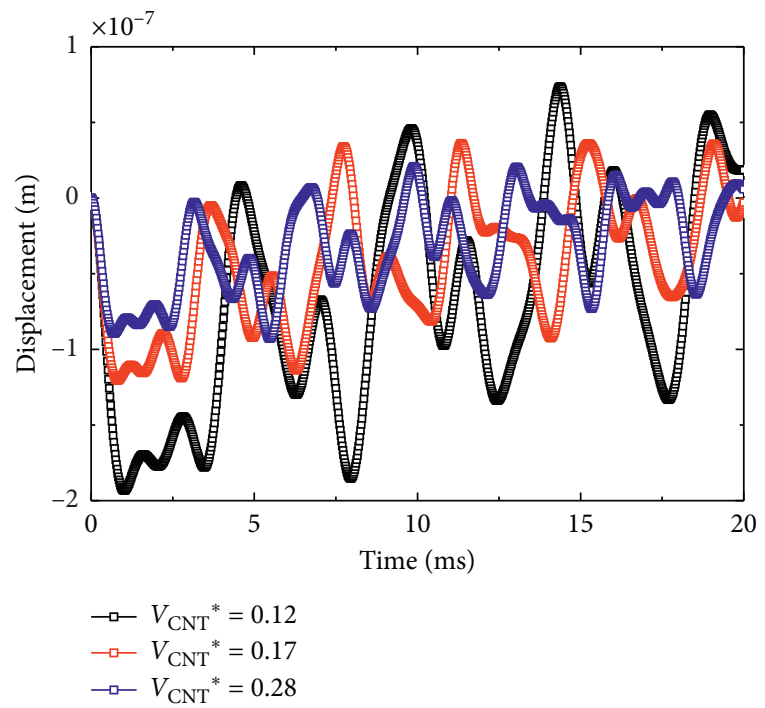

(d)

FIgURE 18: The displacement response of stepped FGPE plate under different pulse types. (a) Rectangular pulse. (b) Triangular pulse. (c) Half-sine pulse. (d) Exponential pulse.

\section{Conclusion}

In this paper, using the domain decomposition method, dynamic behavior of multi-stepped FG-CNTRC plate with random boundary conditions is analyzed based on the FSDT. Within the framework of the domain decomposition method, the rectangular plates are segmented along the length direction using the segmenting technology and the thickness of each subdomain is taken differently. In this way, the multi-stepped FG-CNTRC plate can be constructed simply. The artificial spring technique is employed to satisfy the boundary conditions and the continuity conditions of the piecewise interface. The displacement admissible function of the multi-stepped FG-CNTRC plate is constructed using ultraspherical polynomials in a unified form. The ultraspherical polynomial expansion coefficient is considered as an unknown independent variable, and the dynamic solution equation of the multi-stepped FG-CNTRC plate can be constructed through the calculation of the extremum of the unknown independent variable. As a result, a complex system of partial differential equations is converted into the standard system of linear equations. The accuracy and convergence of the proposed method are validated using numerical examples. Next, the effect of geometric and material parameters on the free vibration characteristics of multi-stepped FG-CNTRC plate is investigated. Several natural frequency parameters and mode shapes which have not been published yet are also introduced in this paper, and they can be referred as comparative data by future researchers. Based on these results, the forced response of the multi-stepped FG-CNTRC plate is also parameterized. The proposed method will be expanded in a 
further work to include multi-stepped cylindrical, conical, and double-curved shell with various boundary conditions.

\section{Data Availability}

The data that support the findings of this study are available within the article.

\section{Conflicts of Interest}

The authors declare that they have no conflicts of interest.

\section{Acknowledgments}

The authors gratefully acknowledge the support from Pyongyang University of Mechanical Engineering of DPRK. The authors would also like to take the opportunity to express their heartfelt gratitude to all those who made contributions to the completion of this article.

\section{Supplementary Materials}

Additional data related to this study can be found in Appendix. (Supplementary Materials)

\section{References}

[1] E. T. Thostenson, Z. Ren, and T.-W. Chou, "Advances in the science and technology of carbon nanotubes and their composites: a review," Composites Science and Technology, vol. 61, no. 13, pp. 1899-1912, 2001.

[2] G. D. Seidel and D. C. Lagoudas, "Micromechanical analysis of the effective elastic properties of carbon nanotube reinforced composites," Mechanics of Materials, vol. 38, no. 8-10, pp. 884-907, 2006.

[3] V. Anumandla and R. F. Gibson, "A comprehensive closed form micromechanics model for estimating the elastic modulus of nanotube-reinforced composites," Composites Part A: Applied Science and Manufacturing, vol. 37, no. 12, pp. 2178-2185, 2006.

[4] A. M. K. Esawi and M. M. Farag, "Carbon nanotube reinforced composites: potential and current challenges," Materials \& Design, vol. 28, no. 9, pp. 2394-2401, 2007.

[5] M. Estili and Y. Sakka, "Recent advances in understanding the reinforcing ability and mechanism of carbon nanotubes in ceramic matrix composites," Science and technology of advanced materials, vol. 15, Article ID 064902, 2014.

[6] H.-S. Shen, "Nonlinear bending of functionally graded carbon nanotube-reinforced composite plates in thermal environments," Composite Structures, vol. 91, no. 1, pp. 9-19, 2009.

[7] K. M. Liew, Z. X. Lei, and L. W. Zhang, "Mechanical analysis of functionally graded carbon nanotube reinforced composites: a review," Composite Structures, vol. 120, pp. 90-97, 2015.

[8] R. Batra and J. Jin, "Natural frequencie SOF a functionally graded anisotropic rectangular plate," Journal of Sound and Vibration, vol. 282, pp. 509-516, 2015.

[9] F. Tornabene, "Free vibration analysis of functionally graded conical, cylindrical shell and annular plate structures with a four-parameter power-law distribution," Computer Methods in Applied Mechanics and Engineering, vol. 198, no. 37-40, pp. 2911-2935, 2009.
[10] F. Tornabene and E. Viola, "Free vibration analysis of functionally graded panels and shells of revolution," Meccanica, vol. 44, no. 3, pp. 255-281, 2009.

[11] F. Tornabene and E. Viola, "Free vibrations of four-parameter functionally graded parabolic panels and shells of revolution," European Journal of Mechanics-A/Solids, vol. 28, no. 5, pp. 991-1013, 2009.

[12] M. Ebrahimi and M. Najafizadeh, "Free vibration analysis of two-dimensional functionally graded cylindrical shells," Applied Mathematical Modelling, vol. 38, pp. 308-324, 2017.

[13] M. Wali, T. Hentati, A. Jarraya, and F. Dammak, "Free vibration analysis of FGM shell structures with a discrete double directors shell element," Composite Structures, vol. 125, pp. 295-303, 2015.

[14] R. Bahadori and M. M. Najafizadeh, "Free vibration analysis of two-dimensional functionally graded axisymmetric cylindrical shell on Winkler-Pasternak elastic foundation by firstorder shear deformation theory and using Navier-differential quadrature solution methods," Applied Mathematical Modelling, vol. 39, no. 16, pp. 4877-4894, 2015.

[15] Q. Wang, D. Shi, Q. Liang, and F. Pang, "Free vibration of four-parameter functionally graded moderately thick doublycurved panels and shells of revolution with general boundary conditions," Applied Mathematical Modelling, vol. 42, pp. 705-734, 2017.

[16] P. Zhu, Z. X. Lei, and K. M. Liew, "Static and free vibration analyses of carbon nanotube-reinforced composite plates using finite element method with first order shear deformation plate theory," Composite Structures, vol. 94, no. 4, pp. 1450-1460, 2012.

[17] Z. X. Lei, L. W. Zhang, and K. M. Liew, "Free vibration analysis of laminated FG-CNT reinforced composite rectangular plates using the KP-RITZ method," Composite Structures, vol. 127, pp. 245-259, 2015.

[18] L. W. Zhang, Z. X. Lei, and K. M. Liew, "Free vibration analysis of functionally graded carbon nanotube-reinforced composite triangular plates using the FSDT and element-free IMLS-RITZ method," Composite Structures, vol. 120, pp. 189-199, 2015.

[19] L. W. Zhang, Z. X. Lei, and K. M. Liew, "Vibration characteristic of moderately thick functionally graded carbon nanotube reinforced composite skew plates," Composite Structures, vol. 122, pp. 172-183, 2015.

[20] L. W. Zhang, Z. X. Lei, K. M. Liew, and J. L. Yu, "Static and dynamic of carbon nanotube reinforced functionally graded cylindrical panels," Composite Structures, vol. 111, pp. 205212, 2014.

[21] N. Fantuzzi, F. Tornabene, M. Bacciocchi, and R. Dimitri, "Free vibration analysis of arbitrarily shaped functionally graded carbon nanotube-reinforced plates," Composites Part B: Engineering, vol. 115, pp. 348-408, 2017.

[22] P. Malekzadeh and A. R. Zarei, "Free vibration of quadrilateral laminated plates with carbon nanotube reinforced composite layers," Thin-Walled Structures, vol. 82, pp. 221232, 2014

[23] P. Malekzadeh and Y. Heydarpour, "Mixed Navier-layerwise differential quadrature three-dimensional static and free vibration analysis of functionally graded carbon nanotube reinforced composite laminated plates," Meccanica, vol. 50, no. 1, pp. 143-167, 2015.

[24] S. J. Mehrabadi, B. Sobhaniaragh, and V. Pourdonya, "Free vibration analysis of nanocomposite plates reinforced by graded carbon nanotubes based on first-order shear 
deformation plate theory," Advances in Applied Mathematics and Mechanics, vol. 5, no. 1, pp. 90-112, 2013.

[25] Y. Kiani, "Free vibration of carbon nanotube reinforced composite plate on point supports using Lagrangian multipliers," Meccanica, vol. 52, no. 6, pp. 1353-1367, 2017.

[26] Y. Kiani, "Free vibration of FG-CNT reinforced composite skew plates," Aerospace Science and Technology, vol. 58, pp. 178-188, 2016.

[27] M. Mirzaei and Y. Kiani, "Free vibration of functionally graded carbon-nanotube-reinforced composite plates with cutout," Beilstein Journal of Nanotechnology, vol. 7, pp. 511523, 2016.

[28] Y. Kiani, "Free vibration of functionally graded carbon nanotube reinforced composite plates integrated with piezoelectric layers," Computers \& Mathematics with Applications, vol. 72, no. 9, pp. 2433-2449, 2016.

[29] Q. Wang, R. Zhong, B. Qin, and H. Yu, "Dynamic analysis of stepped functionally graded piezoelectric plate with general boundary conditions," Smart Materials and Structures, vol. 29, Article ID 035022, 2020.

[30] A. Alibeigloo and A. Emtehani, "Static and free vibration analyses of carbon nanotube-reinforced composite plate using differential quadrature method," Meccanica, vol. 50, no. 1, pp. 61-76, 2015.

[31] E. García-Macías, R. Castro-Triguero, E. I. Saavedra Flores, M. I. Friswell, and R. Gallego, "Static and free vibration analysis of functionally graded carbon nanotube reinforced skew plates," Composite Structures, vol. 140, pp. 473-490, 2016.

[32] F. Lin and Y. Xiang, "Vibration analysis of carbon nanotube reinforced composite plates," Applied Mechanics and Materials, vol. 553, pp. 681-686, 2014.

[33] P. Malekzadeh, M. Dehbozorgi, and S. M. Monajjemzadeh, "Vibration of functionally graded carbon nanotube-reinforced composite plates under a moving load," Science and Engineering of Composite Materials, vol. 22, no. 1, pp. 37-55, 2015.

[34] B. A. Selim, L. W. Zhang, and K. M. Liew, "Vibration analysis of CNT reinforced functionally graded composite plates in a thermal environment based on Reddy's higher-order shear deformation theory," Composite Structures, vol. 156, pp. 276-290, 2016.

[35] K. Mehar, S. Panda, A. Dehengia, and V. R. Kar, "Vibration analysis of functionally graded carbon nanotube reinforced composite plate in thermal environment," Journal of Sandwich Structures \& Materials, vol. 18, pp. 151-173, 2014.

[36] N. Wattanasakulpong and A. Chaikittiratana, "Exact solutions for static and dynamic analyses of carbon nanotube-reinforced composite plates with Pasternak elastic foundation," Applied Mathematical Modelling, vol. 39, no. 18, pp. 54595472, 2015.

[37] A. Ghorbani Shenas, P. Malekzadeh, and S. Ziaee, "Vibration analysis of pre-twisted functionally graded carbon nanotube reinforced composite beams in thermal environment," Composite Structures, vol. 162, pp. 325-340, 2017.

[38] L.-L. Ke, J. Yang, and S. Kitipornchai, "Nonlinear free vibration of functionally graded carbon nanotube-reinforced composite beams," Composite Structures, vol. 92, no. 3, pp. 676-683, 2010.

[39] R. Ansari, M. Faghih Shojaei, V. Mohammadi, R. Gholami, and F. Sadeghi, "Nonlinear forced vibration analysis of functionally graded carbon nanotube-reinforced composite Timoshenko beams," Composite Structures, vol. 113, no. 1, pp. 316-327, 2014.
[40] S. H. Tagrara, A. Benachour, M. B. Bouiadjra, and A. Tounsi, "On bending, buckling and vibration responses of functionally graded carbon nanotube-reinforced composite beams," Steel and Composite Structures, vol. 19, no. 5, pp. 1259-1277, 2015.

[41] H.-S. Shen, X.-Q. He, and D.-Q. Yang, "Vibration of thermally postbuckled carbon nanotube-reinforced composite beams resting on elastic foundations," International Journal of NonLinear Mechanics, vol. 91, pp. 69-75, 2017.

[42] B.S. Aragh, A.N. Barati, and H. Hedayati, "Eshelby-MoriTanaka approach for vibrational behavior of continuously graded carbon nanotube-reinforced cylindrical panels," Composites Part B: Engineering, vol. 43, pp. 1943-1954, 2012.

[43] N. Jooybar, P. Malekzadeh, and A. Fiouz, "Vibration of functionally graded carbon nanotubes reinforced composite truncated conical panels with elastically restrained against rotation edges in thermal environment," Composites Part B: Engineering, vol. 106, pp. 242-261, 2016.

[44] M. Shojaee, A. R. Setoodeh, and P. Malekzadeh, "Vibration of functionally graded CNTS-reinforced skewed cylindrical panels using a transformed differential quadrature method," Acta Mechanica, vol. 228, no. 7, pp. 2691-2711, 2017.

[45] N. Jooybar, P. Malekzadeh, A. Fiouz, and M. Vaghefi, "Thermal effect on free vibration of functionally graded truncated conical shell panels," Thin-Walled Structures, vol. 103, pp. 45-61, 2016.

[46] M. Mirzaei and Y. Kiani, "Free vibration of functionally graded carbon nanotube reinforced composite cylindrical panels," Composite Structures, vol. 142, pp. 45-56, 2016.

[47] Y. Kiani, "Free vibration of FG-CNT reinforced composite spherical shell panels using Gram-Schmidt shape functions," Composite Structures, vol. 159, pp. 368-381, 2016.

[48] Y. Kiani, "Analysis of FG-CNT reinforced composite conical panel subjected to moving load using Ritz method," ThinWalled Structures, vol. 119, pp. 47-57, 2017.

[49] H.-S. Shen and Y. Xiang, "Nonlinear vibration of nanotubereinforced composite cylindrical panels resting on elastic foundations in thermal environments," Composite Structures, vol. 111, pp. 291-300, 2014.

[50] Y. Kiani, "Dynamics of FG-CNT reinforced composite cylindrical panel subjected to moving load," Thin-Walled Structures, vol. 111, pp. 48-57, 2017.

[51] Q. Wang, F. Pang, B. Qin, and Q. Liang, "A unified formulation for free vibration of functionally graded carbon nanotube reinforced composite spherical panels and shells of revolution with general elastic restraints by means of the Rayleigh-Ritz method," Polymer Composites, vol. 39, no. S2, pp. E924-E944, 2017.

[52] Q. Wang, B. Qin, D. Shi, and Q. Liang, "A semi-analytical method for vibration analysis of functionally graded carbon nanotube reinforced composite doubly-curved panels and shells of revolution," Composite Structures, vol. 174, pp. 87109, 2017.

[53] F. Tornabene, N. Fantuzzi, M. Bacciocchi, and E. Viola, "Effect of agglomeration on the natural frequencies of functionally graded carbon nanotube-reinforced laminated composite doubly-curved shells," Composites Part B: Engineering, vol. 89, pp. 187-218, 2016.

[54] Y. Heydarpour, M. M. Aghdam, and P. Malekzadeh, "Free vibration analysis of rotating functionally graded carbon nanotube-reinforced composite truncated conical shells," Composite Structures, vol. 117, pp. 187-200, 2014.

[55] R. Ansari, J. Torabi, and M. F. Shojaei, "Vibrational analysis of functionally graded carbon nanotube-reinforced composite 
spherical shells resting on elastic foundation using the variational differential quadrature method," European Journal of Mechanics-A/Solids, vol. 60, pp. 166-182, 2016.

[56] H.-S. Shen and Y. Xiang, "Nonlinear vibration of nanotubereinforced composite cylindrical shells in thermal environments," Computer Methods in Applied Mechanics and Engineering, vol. 213-216, pp. 196-205, 2012.

[57] Q. Wang, X. Cui, B. Qin, and Q. Liang, "Vibration analysis of the functionally graded carbon nanotube reinforced composite shallow shells with arbitrary boundary conditions," Composite Structures, vol. 182, pp. 364-379, 2017.

[58] Z. Qin, X. Pang, B. Safaei, and F. Chu, "Free vibration analysis of rotating functionally graded CNT reinforced composite cylindrical shells with arbitrary boundary conditions," Composite Structures, vol. 220, pp. 847-860, 2019.

[59] K. Choe, K. Kim, and Q. Wang, "Dynamic analysis of composite laminated doubly-curved revolution shell based on higher order shear deformation theory," Composite Structures, vol. 225, Article ID 111155, 2019.

[60] J. G. Saw, Ultraspherical Polynomials. Wiley StatsRef: Statistics Reference Online, John Wiley \& Sons, Ltd, Hoboken, NJ, USA, 2014.

[61] R. Askey and M. E.-H. Ismail, "A generalization of ultraspherical polynomials," Studies in Pure Mathematics, Springer, Berlin, Germany, pp. 55-78, 1983.

[62] Y. K. Liu, "Application of ultraspherical polynomials to nonlinear forced oscillations," Journal of Applied Mechanics, vol. 34, no. 1, pp. 223-226, 1967.

[63] K. Kim, S. Kim, K. Sok, C. Pak, and K. Han, "A modeling method for vibration analysis of cracked beam with arbitrary boundary condition," Journal of Ocean Engineering and Science, vol. 3, no. 4, pp. 367-381, 2018.

[64] W. M. Abd-Elhameed and Y. H. Youssri, "New spectral solutions of multi-term fractional-order initial value problems with error analysis," Computer Modeling in Engineering and Sciences, vol. 105, pp. 375-398, 2015.

[65] G. Jin, Z. Su, S. Shi, T. Ye, and S. Gao, "Three-dimensional exact solution for the free vibration of arbitrarily thick functionally graded rectangular plates with general boundary conditions," Composite Structures, vol. 108, pp. 565-577, 2014.

[66] K. Itakura, "Free vibration analysis of thick skewed plates having arbitrary boundary conditions," Journal of Structural and Construction Engineering (Transactions of AIJ), vol. 62, no. 492, pp. 37-45, 1997.

[67] K. M. Liew, K. C. Hung, and M. K. Lim, "A continuum threedimensional vibration analysis of thick rectangular plates," International Journal of Solids and Structures, vol. 30, no. 24, pp. 3357-3379, 1993.

[68] K. M. Liew, K. C. Hung, and M. K. Lim, "Free vibration studies on stress-free three-dimensional elastic solids," Journal of Applied Mechanics, vol. 62, no. 1, pp. 159-165, 1995.

[69] J. Guo, D. Shi, Q. Wang, J. Tang, and C. Shuai, "Dynamic analysis of laminated doubly-curved shells with general boundary conditions by means of a domain decomposition method," International Journal of Mechanical Sciences, vol. 138-139, pp. 159-186, 2018. 